\title{
Age-Dependent Remarkable Regenerative Potential of the Dentate Gyrus Provided by Intrinsic Stem Cells
}

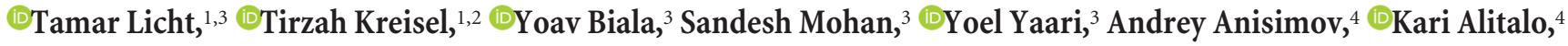 \\ and Eli Keshet ${ }^{1}$ \\ ${ }^{1}$ Department of Developmental Biology and Cancer Research, Faculty of Medicine, Hebrew University, Jerusalem 91120, Israel, ${ }^{2}$ Edmond and Lily Safra \\ Center for Brain Sciences, Hebrew University Givat Ram, Jerusalem 91904, Israel, ${ }^{3}$ Department of Medical Neurobiology, Faculty of Medicine, Hebrew \\ University, Jerusalem 91120, Israel, and ${ }^{4}$ Translational Cancer Biology Program, Research Programs Unit, Faculty of Medicine, University of Helsinki, \\ Finland FI-00014
}

Multiple insults to the brain lead to neuronal cell death, thus raising the question to what extent can lost neurons be replenished by adult neurogenesis. Here we focused on the hippocampus and especially the dentate gyrus (DG), a vulnerable brain region and one of the two sites where adult neuronal stem cells (NSCs) reside. While adult hippocampal neurogenesis was extensively studied with regard to its contribution to cognitive enhancement, we focused on their underestimated capability to repair a massively injured, nonfunctional DG. To address this issue, we inflicted substantial DG-specific damage in mice of either sex either by diphtheria toxin-based ablation of $>50 \%$ of mature DG granule cells (GCs) or by prolonged brain-specific VEGF overexpression culminating in extensive, highly selective loss of DG GCs (thereby also reinforcing the notion of selective DG vulnerability). The neurogenic system promoted effective regeneration by increasing NSCs proliferation/survival rates, restoring a nearly original DG mass, promoting proper rewiring of regenerated neurons to their afferent and efferent partners, and regaining of lost spatial memory. Notably, concomitantly with the natural age-related decline in the levels of neurogenesis, the regenerative capacity of the hippocampus also subsided with age. The study thus revealed an unappreciated regenerative potential of the young DG and suggests hippocampal NSCs as a critical reservoir enabling recovery from catastrophic DG damage.

Key words: adult neurogenesis; dentate gyrus; hippocampal plasticity; neural stem cells; regeneration; VEGF

\section{Significance Statement}

Adult hippocampal neurogenesis has been extensively studied in the context of its role in cognitive enhancement, but whether, and to what extent can dentate gyrus (DG)-resident neural stem cells drive regeneration of an injured DG has remained unclear. Here we show that DG neurogenesis acts to replace lost neurons and restore lost functions even following massive ( $>50 \%)$ neuronal loss. Age-related decline of neurogenesis is paralleled by a progressive decline of regenerative capacity. Considering also the exceptional vulnerability of the DG to insults, these findings provide a further rationale for maintaining DG neurogenesis in adult life.

\section{Introduction}

Stem cells in adult organs are engaged in homeostatic maintenance of the tissue, both in balancing normal cell turnover, as well as in tissue repair following injury.

\footnotetext{
Received May 5, 2019; revised Dec. 11, 2019; accepted Dec. 12, 2019.

Author contributions: T.L., T.K., and E.K. designed research; T.L., T.K., Y.B., and S.M. performed research;T.L., T.K., and Y.B. analyzed data; T.L. wrote the first draft of the paper; T.L. and E.K. wrote the paper; T.K. edited the paper; Y.Y., A.A., and K.A. contributed unpublished reagents/analytic tools.

This work was supported by a European Council Research Project VASNICHE Grant 322692. We thank Steffen Jung (Weizmann Institute), Grigori Enikolopov (Cold Spring Harbor Laboratory), and Rudolf Jaenisch (Massachusetts Institute of Technology) for mice; and Alissa Greenwald and Brachi Wolf (Hebrew University) for assistance. The authors declare no competing financial interests.

Correspondence should be addressed to Tamar Licht at tamarli@ekmd.huji.ac.il or Eli Keshet at elik@ekmd.huji.ac.il.
}

In the brain, neural stem cells (NSCs) mostly reside in two locales: the subventricular zone (SVZ) and the hippocampal dentate gyrus (DG). The major role of SVZ NSCs is the replenishment of olfactory bulb interneurons in compensation for their normal turnover. SVZ-born neuroblasts migrate rostrally to the olfactory bulb via a designated route known as the rostral migratory stream (RMS). While it was shown that SVZ-born neurons can use alternative routes and home to injured brain areas in models of stroke and ischemia (Nakatomi et al., 2002; Zhang et al., 2004; Grade et al., 2013), it is unclear whether they also contribute to functional repair (Inta and Gass, 2015; Lu et al., 2017). 
Table 1. Statistical analysis for all quantifications

\begin{tabular}{|c|c|c|c|c|c|}
\hline Figure & N & Statistical test & $\begin{array}{l}F \text { values main } \\
\text { effect } / T \text { value }\end{array}$ & $\begin{array}{l}p \text { value main } \\
\text { effect }\end{array}$ & $p$ value ( post hoc) \\
\hline $1 H, D G$ height & $\begin{array}{l}\text { Control: } 6 \\
20 \text { dpi: } 7 \\
90 \mathrm{dpi}: 5\end{array}$ & One-way ANOVA & $F_{(2,12)}=16.508$ & $p=3.58 \times 10^{-4}$ & $\begin{array}{l}20 \mathrm{dpi} \text { versus Control: } p=2.54 \times 10^{-4} \\
20 \mathrm{dpi} \text { versus } 90 \mathrm{dpi}: p=0.027\end{array}$ \\
\hline $1 H, \mathrm{GCL}$ thickness & $\begin{array}{l}\text { Control: } 6 \\
20 \text { dpi: } 7 \\
90 \text { dpi: } 5\end{array}$ & One-way ANOVA & $F_{(2,12)}=28.8$ & $p=2.62 \times 10^{-5}$ & $\begin{array}{l}20 \text { dpi versus Control: } p=3.84 \times 10^{-5} \\
20 \mathrm{dpi} \text { versus } 90 \mathrm{dpi} ; p=1.02 \times 10^{-4}\end{array}$ \\
\hline $1 H$, MF thickness & $\begin{array}{l}\text { Control: } 6 \\
20 \text { dpi: } 5 \\
90 \text { dpi: } 3\end{array}$ & One-way ANOVA & $F_{(2,11)}=44.908$ & $p=5.11 \times 10^{-6}$ & $\begin{array}{l}20 \mathrm{dpi} \text { versus Control: } p=4.61 \times 10^{-6} \\
20 \mathrm{dpi} \text { versus } 90 \mathrm{dpi}: p=1.92 \times 10^{-4}\end{array}$ \\
\hline $1 H$, NeuN density & $\begin{array}{l}\text { Control: } 6 \\
20 \text { dpi: } 7 \\
90 \text { dpi: } 5\end{array}$ & One-way ANOVA & $F_{(2,12)}=20.67$ & $p=0.0002$ & $\begin{array}{l}20 \text { dpi versus Control: } p=0.004 \\
20 \text { dpi versus } 90 \mathrm{dpi}: p=0.0026\end{array}$ \\
\hline $2 B$ & $\begin{array}{l}\text { Control: } 10 \\
20 \text { dpi: } 13\end{array}$ & $t$ test & $T_{(21)}=0.4254$ & $p=0.6747$ & \\
\hline $2 F$, active NSCs density & $\begin{array}{l}\text { Control: } 5 \\
20 \mathrm{dpi}: 6\end{array}$ & $t$ test & $T_{(9)}=5.800$ & $p=0.0007$ & \\
\hline $2 F$, active NSCs fraction & $\begin{array}{l}\text { Control: } 5 \\
20 \mathrm{dpi}: 6\end{array}$ & $t$ test & $T_{(9)}=5.542$ & $p=0.0015$ & \\
\hline $2 F$, total neuroblast density & $\begin{array}{l}\text { Control: } 5 \\
20 \text { dpi: } 6\end{array}$ & $t$ test & $T_{(9)}=4.516$ & $p=0.0027$ & \\
\hline $2 F$, early neuroblasts density & $\begin{array}{l}\text { Control: } 5 \\
20 \mathrm{dpi}: 7\end{array}$ & $t$ test & $T_{(10)}=4.883$ & $p=0.0028$ & \\
\hline $2 F$, early neuroblasts fraction & $\begin{array}{l}\text { Control: } 5 \\
20 \mathrm{dpi}: 7\end{array}$ & $t$ test & $T_{(10)}=1.140$ & $p=0.837$ & \\
\hline $2 \mathrm{H}$, newborn neuron density & $\begin{array}{l}\text { Control: } 5 \\
90 \text { dpi: } 6\end{array}$ & $t$ test & $T_{(9)}=4.977$ & $p=0.0025$ & \\
\hline $2 \mathrm{H}$, neuron fraction/total CldU & $\begin{array}{l}\text { Control: } 5 \\
90 \text { dpi: } 6\end{array}$ & $t$ test & $T_{(9)}=3.208$ & $p=0.0125$ & \\
\hline $3 C$ & $\begin{array}{l}1 \text { month: } \\
\text { Control: } 11 \\
\text { VEGF: } 15 \\
2 \text { months: } \\
\text { Control: } 11 \\
\text { VEGF: } 15 \\
3 \text { months: } \\
\text { Control: } 14 \\
\text { VEGF: } 13 \\
4 \text { months: } \\
\text { Control: } 13 \\
\text { VEGF: } 15 \\
\text { 5 months: } \\
\text { Control: } 15 \\
\text { VEGF: } 18 \\
\text { 7m: } \\
\text { Control: } 11 \\
\text { VEGF: } 11\end{array}$ & Two-way ANOVA & $\begin{array}{l}\text { Treatment: } F_{(1,158)}=169.19 \\
\text { Time: } F_{(5,158)}=20.067 \\
\text { Time } \times \text { treatment interaction } \\
\quad(\text { control/VEGF }) \times \text { time: } \\
F_{(5,158)}=5.384\end{array}$ & $\begin{array}{l}\text { Treatment: } p=9.26 \times 10^{-27} \\
\text { Time: } p=1.82 \times 10^{-15} \\
\text { Interaction: } p=1.339 \times 10^{-4}\end{array}$ & $\begin{array}{l}\text { Control versus VEGF: } \\
\qquad \begin{array}{l}1 \text { month: } p=5.82 \times 10^{-4} \\
2 \text { months: } p=5.11 \times 10^{-4} \\
3 \text { months: } p=0.008 \\
4 \text { months: } p=9.48 \times 10^{-9} \\
5 \text { months: } p=1.74 \times 10^{-6} \\
7 \text { months: } p=3.17 \times 10^{-7}\end{array}\end{array}$ \\
\hline $3 D$ & $\begin{array}{l}\text { Control: } 60 \\
1 \text { month: } 61 \\
2 \text { months: } 15 \\
3 \text { months: } 46 \\
4 \text { months: } 16 \\
5 \text { months: } 18 \\
7 \text { months: } 11\end{array}$ & One-way ANOVA & $F_{(6,225)}=88.892$ & $p=1.39 \times 10^{-6}$ & $\begin{array}{l}\text { Control versus } 2 \text { months: } \\
p=4.2 \times 10^{-06} \\
\text { Control versus } 3 \text { months: } \\
p=1.45 \times 10^{-22} \\
\text { Control versus } 4 \text { months: } \\
p=1.53 \times 10^{-19} \\
\text { Control versus } 5 \text { months: } \\
p=8.32 \times 10^{-18} \\
\text { Control versus } 7 \text { months: } \\
p=5.75 \times 10^{-34}\end{array}$ \\
\hline $4 B$ & $\begin{array}{l}\text { Control: } 13 \\
\text { VEGF: } 10\end{array}$ & $t$ test & $\begin{array}{l}\text { CA1: } I_{(21)}=-10.752 \\
\text { DG: } T_{(21)}=-8.237\end{array}$ & $\begin{array}{l}\text { CA1: } p=9.21 \times 10^{-10} \\
\text { DG: } p=7.39 \times 10^{-8}\end{array}$ & \\
\hline $4 C$ & $\begin{array}{l}\text { Control: } 12 \\
\text { VEGF: } 10 \\
\text { No transgene: } 4 \\
\text { tTa only: } 4 \\
\text { tTa-tetGFP: } 5\end{array}$ & One-way ANOVA & $\begin{array}{l}\text { CA1 neuron density: } \\
\quad T_{(20)}=-0.047 \\
\text { CA1 height: } T_{(20)}=-3.63 \\
\text { GCL thickness: } F_{(2,12)}=0.6605 \\
\text { DG height: } F_{(2,12)}=1.906\end{array}$ & $\begin{array}{l}\text { CA1 neuron density: } p=0.7 \\
\text { CA1 height: } p=0.002 \\
\text { GCL thickness: } p=0.5378 \\
\text { DG height: } p=0.199\end{array}$ & 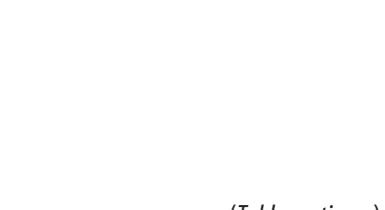 \\
\hline
\end{tabular}


Table 1. Continued

\begin{tabular}{|c|c|c|c|c|c|}
\hline Figure & $N$ & Statistical test & $\begin{array}{l}\text { vvalues main } \\
\text { effect } / T \text { value }\end{array}$ & $\begin{array}{l}p \text { value main } \\
\text { effect }\end{array}$ & $p$ value (post hoc) \\
\hline 60 , NeuN density & $\begin{array}{l}\text { Control: } 8 \\
\text { VEGF on: } 8 \\
\text { VEGF on }>\text { off: } 8\end{array}$ & One-way ANOVA & $F_{(2,21)}=61.526$ & $p=1.655 \times 10^{-9}$ & $\begin{array}{l}\text { Control versus VEGF } 0 \mathrm{n}: \\
p=6.279 \times 10^{-9} \\
\text { Control versus VEGF } 0 \mathrm{n}>\text { off: } \\
p=2.11 \times 10^{-6} \\
\text { VEGF On versus VEGF } 0 \mathrm{n}>\text { off: } \\
\quad p=0.002\end{array}$ \\
\hline $6 D, \mathrm{GCL}$ thickness & $\begin{array}{l}\text { Control: } 18 \\
\text { VEGF on: } 9 \\
\text { VEGF on }>\text { off: } 16\end{array}$ & One-way ANOVA & $F_{(2,40)}=23.589$ & $p=1.7 \times 10^{-7}$ & $\begin{array}{l}\text { Control versus VEGF } 0 \mathrm{n} \text { : } \\
\quad p=6.279 \times 10^{-9} \\
\text { Control versus VEGF } 0 \mathrm{n}>\text { off: } \\
\quad p=2.11 \times 10^{-6} \\
\text { VEGF on versus VEGF } 0 \mathrm{n}>\text { off: } \\
\quad p=0.002\end{array}$ \\
\hline $6 D$, DG height & $\begin{array}{l}\text { Control: } 18 \\
\text { VEGF on: } 9 \\
\text { VEGF on }>\text { off: } 16\end{array}$ & One-way ANOVA & $F_{(2,40)}=30.116$ & $p=1.04 \times 10^{-8}$ & $\begin{array}{l}\text { Control versus VEGF on: } \\
\quad p=1.15 \times 10^{-8} \\
\text { Control versus VEGF on }>\text { off: } \\
\quad p=0.01 \\
\text { VEGF on versus VEGF on }>\text { off: } \\
\quad p=4.76 \times 10^{-4}\end{array}$ \\
\hline $6 D, M F$ thickness & $\begin{array}{l}\text { Control: } 9 \\
\text { VEGF on: } 9 \\
\text { VEGF on }>\text { off: } 7\end{array}$ & One-way ANOVA & $F_{(2,19)}=28.35$ & $p=1.9 \times 10^{-6}$ & $\begin{array}{l}\text { Control versus } 0 \mathrm{n}: p=1.18 \times 10^{-6} \\
\text { Control versus on }>\text { off: } p=0.014 \\
\text { On versus } 0 \mathrm{n}>\text { off: } p=0.01\end{array}$ \\
\hline $6 E$ & On>off 1 month: 12 & Two-way ANOVA & Treatment: $F_{(2,161)}=207.169$ & Treatment: $p=2.99 \times 10^{-45}$ & $\begin{array}{l}\text { Control versus } 3 \text { months on } \\
\quad>1 \text { month off: } \\
\quad 4.83 \times 10^{-13} \\
\text { Control versus } 3 \text { months on } \\
\quad>3 \text { months off: } \\
\quad p=1.65 \times 10^{-4}\end{array}$ \\
\hline & On>off 2 months: 16 & & Time: $F_{(2,161)}=11.382$ & Time: $p=2.37 \times 10^{-5}$ & $\begin{array}{l}5 \text { months on versus } 3 \text { months on } \\
\quad>2 \text { months off: } \\
\qquad p=4.83 \times 10^{-13}\end{array}$ \\
\hline & On>off 3 months: 30 & & Interaction: $F_{(2,161)}=27.373$ & Interaction: $p=5.84 \times 10^{-11}$ & $\begin{array}{l}7 \text { months on versus } \\
\quad \begin{array}{l}3 \text { months on }>3 \text { months } \\
\text { off: } p=4.82 \times 10^{-13}\end{array}\end{array}$ \\
\hline $7 D$, total NSC density & $\begin{array}{l}\text { Control: } 11 \\
\text { VEGF on: } 7 \\
\text { VEGF on }>\text { off: } 13\end{array}$ & One-way ANOVA & $F_{(2,28)}=27.632$ & $p=0.22$ & Control versus VEGF On: $p=0.019$ \\
\hline 7D, active NSC density & $\begin{array}{l}\text { Control: } 11 \\
\text { VEGF on: } 7 \\
\text { VEGF on }>\text { off: } 13\end{array}$ & One-way ANOVA & $F_{(2,28)}=13.39$ & $p=0.0002$ & $\begin{array}{l}\text { Control versus VEGF } 0 \mathrm{n}: \\
\quad \begin{array}{l}p=0.0002 \\
\text { Control versus VEGF } 0 \mathrm{n}>\text { off: } \\
p=0.0002\end{array}\end{array}$ \\
\hline $7 D$, fraction of active NSC & $\begin{array}{l}\text { Control: } 11 \\
\text { VEGF on: } 7 \\
\text { VEGF on }>\text { off: } 13\end{array}$ & One-way ANOVA & $F_{(2,28)}=4.379$ & $p=2.26 \times 10^{-7}$ & $\begin{array}{l}\text { Control versus VEGF On: } \\
\qquad p=4.24 \times 10^{-7} \\
\text { Control versus VEGF On Off: } \\
\quad p=2.03 \times 10^{-5}\end{array}$ \\
\hline $8 B$ & $\begin{array}{l}\text { Control: } 15 \\
\text { VEGF on: } 7 \\
\text { VEGF on }>\text { off: } 12\end{array}$ & One-way ANOVA & $F_{(2,31)}=50.405$ & $p=1.8 \times 10^{-10}$ & $\begin{array}{l}\text { Control versus VEGF } 0 \mathrm{n}>\text { off } \\
\quad p=5.47 \times 10^{-9} \\
\text { VEGF on versus VEGF } 0 \mathrm{n}>\text { off: } \\
\quad p=9.53 \times 10^{-8}\end{array}$ \\
\hline $8 C, M V D$ & $\begin{array}{l}\text { Control: } 19 \\
\text { VEGF on: } 8 \\
\text { VEGF on }>\text { off: } 10\end{array}$ & One-way ANOVA & $F_{(2,34)}=154.153$ & $p=1.84 \times 10^{-9}$ & $\begin{array}{l}\text { Control versus VEGF On: } \\
\qquad p=3.33 \times 10^{-7} \\
\text { Control versus VEGF on }>\text { off: } \\
\quad p=3.47 \times 10^{-8}\end{array}$ \\
\hline $8 C$, total neuroblast density & $\begin{array}{l}\text { Control: } 19 \\
\text { VEGF on: } 7 \\
\text { VEGF on }>\text { off: } 10\end{array}$ & One-way ANOVA & $F_{(2,32)}=58.735$ & $p=1.9 \times 10^{-11}$ & $\begin{array}{l}\text { Control versus VEGF On: } \\
\quad p=5.208 \times 10^{-9} \\
\text { Control versus VEGF on }>\text { off: } \\
\quad p=2.12 \times 10^{-8}\end{array}$ \\
\hline $8 D$, late neuroblast density & $\begin{array}{l}\text { Control: } 14 \\
\text { VEGF on: } 6 \\
\text { VEGF on }>\text { off: } 11\end{array}$ & One-way ANOVA & $F_{(2,28)}=26.836$ & $p=3.09 \times 10^{-7}$ & $\begin{array}{l}\text { Control versus VEGF on } \\
\quad p=1.59 \times 10^{-6} \\
\text { Control versus VEGF on }>\text { off } \\
\quad p=1.69 \times 10^{-5}\end{array}$ \\
\hline
\end{tabular}


Table 1. Continued

\begin{tabular}{|c|c|c|c|c|c|}
\hline Figure & N & Statistical test & $\begin{array}{l}F \text { values main } \\
\text { effect } / T \text { value }\end{array}$ & $\begin{array}{l}p \text { value main } \\
\text { effect }\end{array}$ & $p$ value (post hoc) \\
\hline $8 D$, late neuroblast $\%$ & $\begin{array}{l}\text { Control: } 14 \\
\text { VEGF on: } 6 \\
\text { VEGF on }>\text { off: } 11\end{array}$ & One-way ANOVA & $F_{(2,28)}=6.084$ & $p=0.006$ & $\begin{array}{l}\text { Control versus VEGF on }>\text { off } p=0.01 \\
\text { VEGF on versus VEGF on }>\text { off } p=0.031\end{array}$ \\
\hline $9 D$ & $\begin{array}{l}\text { Control: } 8 \\
\text { VEGF on: } 7 \\
\text { VEGF on }>\text { off: } 9\end{array}$ & One-way ANOVA & $F_{(2,21)}=6.808$ & $p=0.005$ & $\begin{array}{l}\text { Control versus VEGF On: } p=0.004 \\
\text { VEGF } 0 \mathrm{n}>\text { off versus VEGF on: } p=0.028\end{array}$ \\
\hline $9 F$ & $\begin{array}{l}\text { Control: } 15 \\
\text { VEGF: } 9\end{array}$ & Two-way ANOVA & $\begin{array}{l}\text { Treatment: } F_{(1,64)}=10.785 \\
\text { Time: } F_{(2,64)}=10.987 \\
\text { Time } \times \text { treatment interaction: } \\
\quad F_{(2,64)}=4.198\end{array}$ & $\begin{array}{l}\text { Treatment: } p=0.002 \\
\text { Time: } p=7.9 \times 10^{-5} \\
\text { Interaction: } p=0.019\end{array}$ & Control versus VEGF on: $p=0.004$ \\
\hline $10 B$ & $\begin{array}{l}\text { Control: } 18 \\
\text { VEGF on: } 15 \\
\text { VEGF on }>\text { off: } 15\end{array}$ & One-way ANOVA & $F_{(2,45)}=47.84$ & $p=7.27 \times 10^{-12}$ & $\begin{array}{l}\text { Control versus VEGF } 0 \mathrm{n}: p=8.08 \times 10^{-9} \\
\text { Control versus VEGF } 0 \mathrm{n}>\text { off: } p=5.15 \times 10^{-9}\end{array}$ \\
\hline $10 C, 12$ months & $\begin{array}{l}\text { Control: } 7 \\
\text { VEGF on: } 4 \\
\text { VEGF on }>\text { off: } 10\end{array}$ & One-way ANOVA & $F_{(2,29)}=34.5$ & $p=1.55 \times 10^{-5}$ & 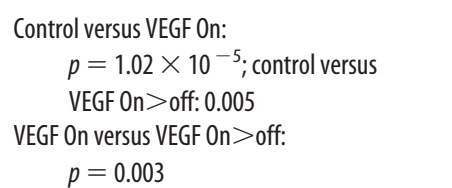 \\
\hline $10 C, 18$ months & $\begin{array}{l}\text { Control: } 10 \\
\text { VEGF on: } 5 \\
\text { VEGF on }>\text { off: } 9\end{array}$ & One-way ANOVA & $F_{(2,21)}=11.07$ & $p=0.001$ & $\begin{array}{l}\text { Control versus VEGF } 0 \mathrm{n}: p=3.93 \times 10^{-4} \\
\quad \text { Control versus VEGF } 0 \mathrm{n}>\text { off: } p=0.048\end{array}$ \\
\hline $10 C$ & $\begin{array}{l}12 \text { months versus } \\
18 \text { months }\end{array}$ & Two-way ANOVA & $\begin{array}{l}\text { Age: } F_{(1,39)}=31.749 \\
\text { Interaction: } F_{(2,39)}=9.031\end{array}$ & $\begin{array}{l}\text { Age: } p=1.66 \times 10^{-6} \\
\text { interaction: } p=0.001\end{array}$ & $\begin{array}{l}\text { VEGF } 0 \mathrm{n} 12 \text { months } \\
\quad \text { versus VEGF on } 18 \text { months: } \\
p=4.4 \times 10^{-5} \\
\text { VEGF } 0 \mathrm{n}>\text { off } 12 \text { months versus } \\
\text { VEGF on }>\text { off } 18 \text { months: } p=0.015\end{array}$ \\
\hline $10 D$ & $\begin{array}{l}12 \text { months: } \\
\text { Control: } 6 \\
\text { VEGF on >off: } 5 \\
18 \text { months: } \\
\text { Control: } 7 \\
\text { VEGF on }>\text { off: } 11\end{array}$ & Two-way ANOVA & $\begin{array}{l}\text { Treatment: } F_{(1,25)}=25.164 \\
\text { Age: } F_{(1,25)}=15.171 \\
\text { Interaction: } F_{(1,25)}=7.44\end{array}$ & $\begin{array}{l}\text { Treatment: } p=3.57 \times 10^{-5} \\
\text { Age: } p=0.001 \\
\text { Interaction: } p=0.011\end{array}$ & $\begin{array}{l}12 \text { months Control versus } 0 \mathrm{n}>\text { off: } \\
p=2.31 \times 10^{-4} 12 \text { months } \\
\text { On }>\text { off versus } 18 \text { months } \\
0 \mathrm{n}>\text { off: } p=3.83 \times 10^{-4}\end{array}$ \\
\hline $10 E$, 12 months & $\begin{array}{l}\text { Control: } 6 \\
\text { VEGF on: } 4 \\
\text { VEGF on }>\text { off: } 11\end{array}$ & One-way ANOVA & $F_{(2,18)}=8.338$ & $p=0.003$ & $\begin{array}{l}\text { Control versus VEGF On: } p=0.04 \\
\text { VEGF On versus VEGF On-off: } p=0.04\end{array}$ \\
\hline $10 E$, 18 months & $\begin{array}{l}\text { Control: } 9 \\
\text { VEGF on: } 5 \\
\text { VEGF on }>\text { off: } 6\end{array}$ & One-way ANOVA & $F_{(2,17)}=20.527$ & $p=2.9 \times 10^{-5}$ & $\begin{array}{l}\text { Control versus VEGF On: } \\
\qquad \begin{array}{l}p=1.37 \times 10^{-5} \\
\text { Control versus VEGF On-off: } \\
p=1.85 \times 10^{-4}\end{array}\end{array}$ \\
\hline $10 E$ & $\begin{array}{l}12 \text { months versus } \\
18 \text { months }\end{array}$ & Two-way ANOVA & $\begin{array}{l}\text { Treatment: } F_{(2,53)}=34.516 \\
\text { Age: } F_{(1,53)}=3.672 \\
\text { Interaction: } F_{(2,53)}=3.166\end{array}$ & $\begin{array}{l}\text { Treatment: } p=2.25 \times 10^{-10} \\
\text { Age: } p=0.032 \\
\text { interaction: } p=0.021\end{array}$ & $\begin{array}{l}\text { On }>\text { off } 12 \text { months versus } \\
\quad \text { On }>\text { off } 18 \text { months: } \\
\quad p=0.0148\end{array}$ \\
\hline $10 F, 12$ months & $\begin{array}{l}\text { Control: } 8 \\
\text { VEGF on: } 5 \\
\text { VEGF on }>\text { off: } 11\end{array}$ & One-way ANOVA & $F_{(2,21)}=7.61$ & $p=0.003$ & $\begin{array}{l}\text { Control versus VEGF On: } \\
\qquad p=0.002\end{array}$ \\
\hline $10 F, 18$ months & $\begin{array}{l}\text { Control: } 11 \\
\text { VEGF on: } 12 \\
\text { VEGF on }>\text { off: } 9\end{array}$ & One-way ANOVA & $F_{(2,29)}=46.408$ & $p=9.16 \times 10^{-10}$ & $\begin{array}{l}\text { Control versus VEGF On: } \\
\quad p=6.43 \times 10^{-9} \\
\text { Control versus VEGF } 0 \mathrm{n}>\text { off: } \\
p=3.06 \times 10^{-7}\end{array}$ \\
\hline $10 F$ & $\begin{array}{l}12 \text { months versus } \\
18 \text { months }\end{array}$ & Two-way ANOVA & $\begin{array}{l}\text { Treatment: } F_{(2,50)}=36.843 \\
\text { Age: } F_{(1,50)}=4.529 \\
\text { Interaction: } F_{(2,50)}=3.192\end{array}$ & $\begin{array}{l}\text { Treatment: } p=1.466 \times 10^{-10} \\
\text { Age: } p=0.038 \\
\text { interaction: } p=0.05\end{array}$ & $\begin{array}{l}\text { On }>\text { off } 12 \text { months versus } 0 \mathrm{n}>0 \text { off } 18 \text { : } \\
\quad p=0.025\end{array}$ \\
\hline $10 G, 12$ months & $\begin{array}{l}\text { Control: } 8 \\
\text { VEGF on: } 5 \\
\text { VEGF on }>\text { off: } 11\end{array}$ & One-way ANOVA & $F_{(2,21)}=8.175$ & $p=0.002$ & $\begin{array}{l}\text { Control versus VEGF } 0 \mathrm{n}: p=0.003 \\
\text { VEGF On versus VEGF } 0 \mathrm{n}>\text { off: } p=0.007\end{array}$ \\
\hline $10 G, 18$ months & $\begin{array}{l}\text { Control: } 11 \\
\text { VEGF on: } 12 \\
\text { VEGF on }>\text { off: } 9\end{array}$ & One-way ANOVA & $F_{(2,29)}=34.5$ & $p=2.14 \times 10^{-8}$ & $\begin{array}{l}\text { Control versus VEGF } 0 \mathrm{n}: \\
\quad p=2.36 \times 10^{-8} \\
\text { Control versus VEGF } 0 \mathrm{n}>\text { off: } \\
\quad p=1.62 \times 10^{-5}\end{array}$ \\
\hline $10 G$ & $\begin{array}{l}12 \text { months versus } \\
18 \text { months }\end{array}$ & Two-way ANOVA & $\begin{array}{l}\text { Treatment: } F_{(2,50)}=30.784 \\
\text { Age } F_{(1,50)}=7.067 \\
\text { Interaction: } F_{(2,50)}=4.568\end{array}$ & $\begin{array}{l}\text { Treatment: } p=1.93 \times 10^{-9} \\
\text { Age: } p=0.011 \\
\text { interaction: } p=0.015\end{array}$ & $\begin{array}{l}\text { On }>\text { off } 12 \text { months versus } 0 \mathrm{n}>\text { off } 18 \text { months: } \\
\quad p=0.0035\end{array}$ \\
\hline
\end{tabular}


A

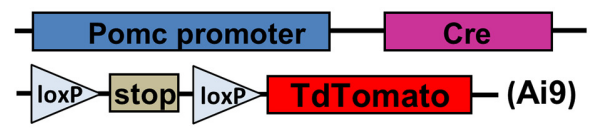

B
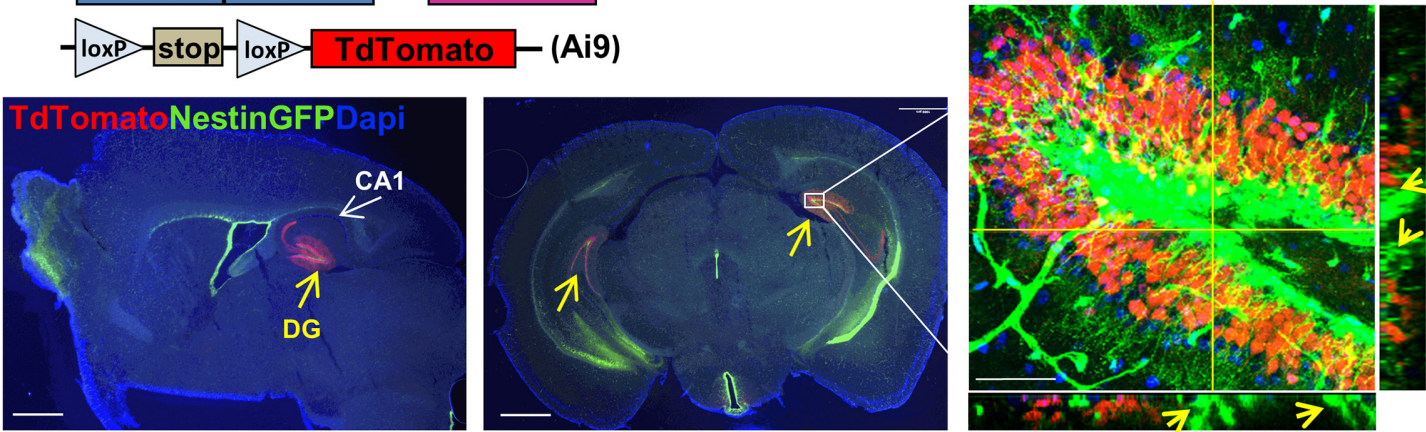

C
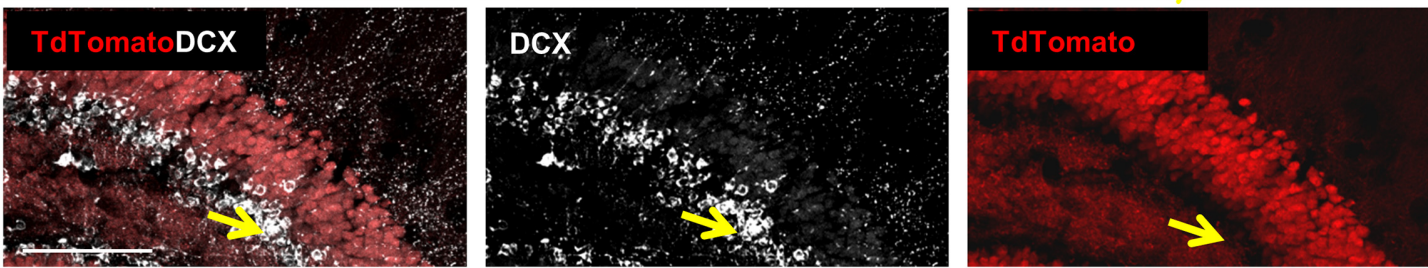

D - Pomc promoter

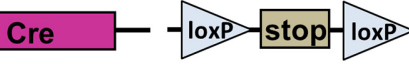

E
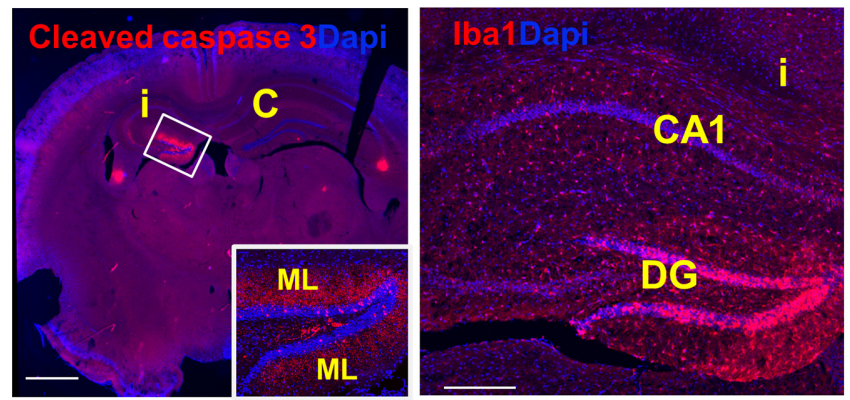

$\mathbf{F}$
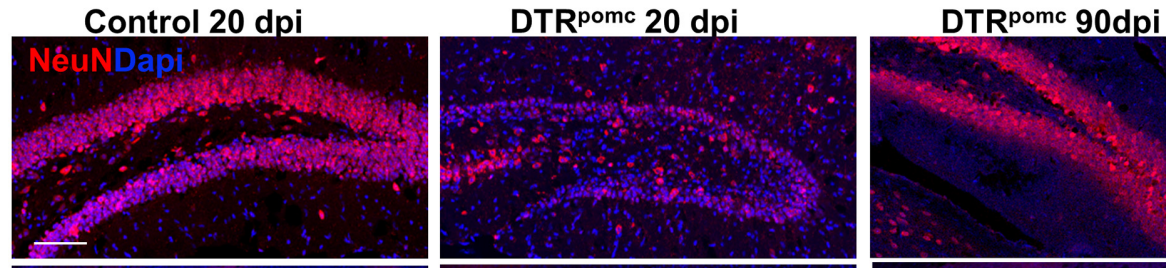

G
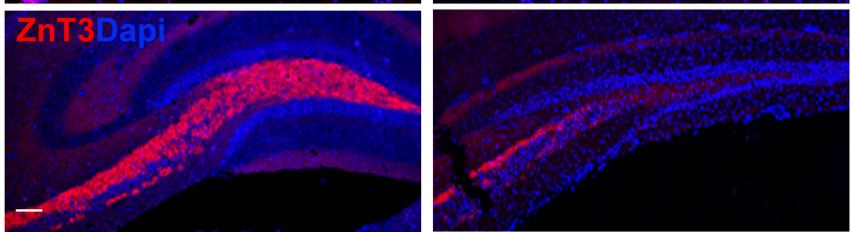

$5 d p i$ -(iDTR)

DTR
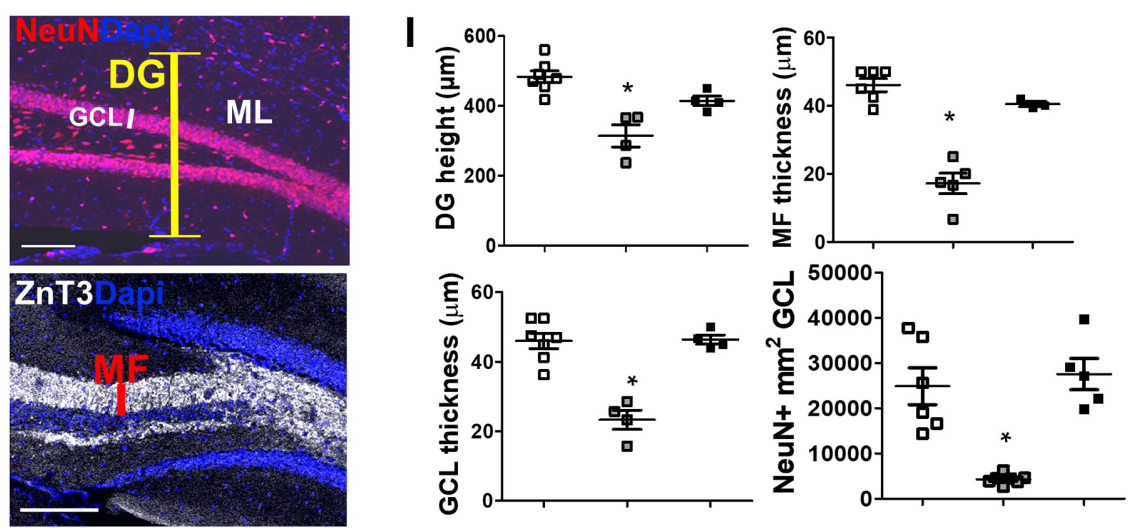

Figure 1. DT-mediated specific ablation of DG GCS. A, Protocol for highlighting the pattern of cre-expressing cells in the POMC-Cre transgenic mouse line with the aid of Ai9 reporter mouse. $\boldsymbol{B}$, Pomc-Cre drives TdTomato reporter expression specifically in the DG (yellow arrows). Right, NSCs distinguished by their tree-like morphology and highlighted by GFP in the Nestin-GFP line do not colocalize with TdTomato (see arrows in z-projection planes). Scale bars: left and middle, $1 \mathrm{~mm}$; right, $50 \mu \mathrm{m}$. C, Pomc-Cre does not drive expression of the TdTomato (Figure legend continues.) 
DG-resident NSCs are engaged in constitutive production of new neurons in rodents and potentially also in humans (Eriksson et al., 1998; Spalding et al., 2013; Boldrini et al., 2018) that integrate within the existing network of DG granule cells (GCs) (van Praag et al., 2002) where they contribute to memory and mood processes (Aimone et al., 2011; Toda et al., 2019). Although neurogenic response was documented in experimental animal models of injury and epilepsy (Gould and Tanapat, 1997; Gray and Sundstrom, 1998; Jessberger et al., 2007; Cho et al., 2015; Yu et al., 2016), the natural role of NSCs in functional DG repair following injury is grossly underappreciated. This issue is of particular significance given the vulnerability of the hippocampus, in general, and of GCs in particular, to damaging insults. Because of the low excitability of GCs and their natural role in moderation of excitatory signals (Heinemann et al., 1992; Krook-Magnuson et al., 2015), their loss is a major cause of temporal lobe epilepsy, a pathology further aggravating selective GC loss and often culminating in DG degeneration (Houser, 1992; Steward, 1994). Examining whether DG NSCs are capable of driving functional DG repair in epilepsy models has been hampered by the continual nature of the damage counteracting the repair process (Hattiangady et al., 2004). Likewise, DG neurogenesis induced by kainic acid was shown to be associated with accelerated NSC depletion and astrocytic differentiation rather than neuron production (Sierra et al., 2015).

The exceptional vulnerability of the DG is also evidenced in other human pathologies, such as frontotemporal lobe degeneration, Alzheimer's disease, and adrenal insufficiency (Maehlen and Torvik, 1990; Armstrong et al., 2012; Collins et al., 2012; Kovacs et al., 2013; Takeda and Tamano, 2018) and in rodent models of these and other pathologies that are often associated with enhanced neurogenesis (Spanswick et al., 2007, 2011; Watanabe et al., 2016; Choi et al., 2017; Tu et al., 2018; F. Wang et al., 2018).

To examine the regenerative potential of the DG, we used two independent ways for conditional infliction of GC-specific massive cell death, importantly, under conditions sparing NSCs. In the first model, diphtheria toxin (DT) injected to adult mice expressing DT receptors exclusively in GCs leads to selective elimination of $>50 \%$ of GCs. In the second model, a comparable GC-specific loss is caused by conditionally induced prolonged (>3 months) overexpression of VEGF. Importantly, the damaging insult in this tetracycline-regulated VEGF system can be terminated at will, thus providing a unique opportunity to uncouple the processes of DG injury and repair. Here we uncovered a remarkable regenerative capacity of the DG, not only with respect to replenishing lost neurons but also with respect to

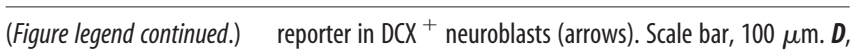
Experimental protocol for Cre-mediated cell ablation using iDTR mice for conditional expression of DTR (DTR $\left.{ }^{\text {pomc }}\right)$.E, DT ( $5 \mathrm{ng}$ ) was injected to the left hippocampus of DTR ${ }^{\text {pomc }}$ mice, and brains were retrieved $5 \mathrm{~d}$ thereafter. Cleaved caspase 3 immunostaining illustrates a DG-restricted injury (left), and lba1 immunostaining highlights microglia clustering in the injured $\mathrm{GCL}$ of the DG (right). i, I psilateral; c, contralateral. Scale bars: left, $1 \mathrm{~mm}$; right, $200 \mu \mathrm{m}$. F, G, DT (3 ng) was injected bilaterally to the hippocampus of control (iDTR monotransgenic) or DTR ${ }^{\text {pomc }}$ mice, and brains were retrieved 20 or $90 \mathrm{~d}$ later. A substantial loss of GCs in DTR ${ }^{\text {pomc }}$ mice is indicated at 20 dpi by NeuN immunostaining highlighting $\mathrm{GC}$ cell bodies $(\boldsymbol{F})$ and by ZnT3 immunostaining highlighting their MF axons (G.) Near-complete recovery is indicated at 90 dpi. Scale bar, 100 $\mu \mathrm{m} . \boldsymbol{H}, \mathrm{DG}$ height (yellow bar), GCL thickness (white bar), and thickness of the MF layer (red bar) used as quantifiable parameters of DG repair (shown in control DG). Scale bar, $100 \mu \mathrm{m} . I$, Quantification of DG regeneration comparing noninjured, injured (at 20 dpi), and repaired (at 90 dpi) hippocampi. For statistical details, see Table $1 .{ }^{*} p<0.0005$.
}

proper rewiring and restoration of lost cognitive functions. We further show that regeneration is driven by DG NSCs and that progressive neurogenesis decline with age (Kuhn et al., 1996; Ben Abdallah et al., 2010; Encinas et al., 2011) is accompanied by a progressive diminishment of the regenerative potential.

\section{Materials and Methods}

Mice. All animal procedures were approved by the Animal Care and Use Committee of Hebrew University. Transgenic mouse lines that were used in this study are as follows: CamkII $\alpha-t T A, A i 9$, Pomc-Cre, iDTR, and Gli1-cre $e^{E R T 2}$ lines were purchased from the The Jackson Laboratory (strains 016198, 007909, 010714, 007900, 007913). pTET-VEGF ${ }_{164}$ and pTET-sVEGFR1 responder lines were as described previously (Licht et al., 2011). Nestin-GFP line was obtained from Prof. Grigori Enikolopov, Cold Spring Harbor Laboratory (Mignone et al., 2004). pTET-GFP line was obtained from R. Jaenisch, Massachusetts Institute of Technology (Beard et al., 2006). Both males and females were used. For switching-off VEGF, water was supplemented by $500 \mathrm{mg} / \mathrm{L}$ tetracycline (Bio Basic Canada, \#TB0504) and 3\% sucrose. For switching on the transgene, tetracycline-supplemented water was replaced by fresh water for the desired time. Chloro-deoxyuridine (CldU; MP Biomedicals, \#02105478 $100 \mathrm{mg} / \mathrm{kg}$ ) or iodo-deoxyuridine (IdU) (Sigma Millipore, I7125, 100 $\mathrm{mg} / \mathrm{kg}$ ) were injected intraperitoneally 3 times at $8 \mathrm{~h}$ intervals at the indicated time points. Tamoxifen (Sigma Millipore, T5648, $40 \mathrm{mg} / \mathrm{ml}$ in sunflower seed oil) was administered orally once daily for $5 \mathrm{~d}$ at a dose of $\sim 8 \mathrm{mg}$ /animal. TRITC-labeled $10 \mathrm{kDa}$ dextran (Invitrogen, \#1817) was injected intracardially at $100 \mathrm{~g} / \mathrm{kg} 2 \mathrm{~min}$ before death. Animals were grown in SPF housing conditions with irradiated rodent food and water/ tetracycline ad libitum. Breeding cages for the VEGF system include males heterozygous for pTET-VEGF ${ }_{164}$, CamkII $\alpha$-tTA, and Ai9/NestinGFP alleles and females heterozygous for CamkII $\alpha-t T A$ and Gli1creERT2/Nestin-GFP (maternal imprinting of the pTET-VEGF ${ }_{164}$ allele results in high mortality upon VEGF induction). Mice that inherited the CamkII $\alpha$-tTA alone served as controls for CamkII $\alpha$-tTA; pTET$V E G F_{164}$ double-transgenic littermates. All animals in experiments (controls and VEGF) were kept in the same cage and received the same treatment. Litters of either sex were used.

Intrahippocampal injections. Mice were anesthetized with an intraperitoneal injection of ketamine/xylazine followed by isoflurane inhalation. The head was placed in a stereotactic apparatus (Stoelting), and a burr hole was drilled at the injection site using the following coordinates relative to bregma (in $\mathrm{mm}$ ): anteroposterior: $-2.5 \mathrm{~mm}$, mediolateral: $-1.4 \mathrm{~mm}$, dorsoventral: $-2 \mathrm{~mm}$. Injections were conducted using a 10 $\mu$ l syringe (Hamilton) and a thin 33-gauge metal needle (WPI). DT (Merck Millipore, \#322326, $5 \mu \mathrm{g} / \mathrm{ml}$ ) or adeno-associated virus (AAV)$\operatorname{VEGF}(3 \mathrm{E}+06 \mathrm{vp} / \mu \mathrm{l})($ Kivelä et al., 2019) was dissolved in saline, and $1 \mu \mathrm{l}$ was delivered at a flow rate of $0.4 \mu \mathrm{l} / \mathrm{min}$. After injection, the needle was left in place for 5 additional minutes and then slowly withdrawn. For bilateral injections (mediolateral: $\pm 1.4 \mathrm{~mm}$ ), a $0.7 \mu \mathrm{l}$ of DT in each hemisphere was administered. All mice received DT injections while mice inherited iDTR alone served as controls. For AAV experiment, an empty AAV vector served as control.

Electrophysiology. Mice were decapitated under isoflurane anesthesia, and coronal hippocampal slices $(350 \mu \mathrm{m})$ were prepared with a vibratome and transferred to a storage chamber perfused with oxygenated ( $95 \% \mathrm{O}_{2} / 5 \% \mathrm{CO}_{2}$ ) aCSF at room temperature (containing the following, in $\mathrm{mm}$ ): $130 \mathrm{NaCl}, 3.5 \mathrm{KCl}, 1 \mathrm{MgSO}_{4}, 1.6 \mathrm{CaCl}_{2}, 24 \mathrm{NaHCO}_{3}$, and 10 D-glucose). For recording, slices were placed one at a time in an interface chamber and superfused (flow rate $1 \mathrm{ml} / \mathrm{min}$ ) with warmed $\left(35^{\circ} \mathrm{C}\right)$ oxygenated aCSF. The temperature was measured with a thermal probe juxtaposed to the slice and maintained at $35^{\circ} \mathrm{C}$ with a feedback controller (NPI). Bipolar tungsten $(115 \mu \mathrm{m})$ electrodes (FHC) connected to a stimulator by an isolation unit were used for focal stimulation $(1-20 \mathrm{~V}, 50 \mu \mathrm{s})$ of afferent fibers of perforant path axons. Extracellular recordings were performed with glass electrodes containing $3 \mathrm{M} \mathrm{NaCl}(5-10 \mathrm{M} \Omega)$, at the upper blade of the granule cell layer (GCL). An amplifier (EXT-10C, NPI Electronic) was used, allowing measurement of field potentials of cell 


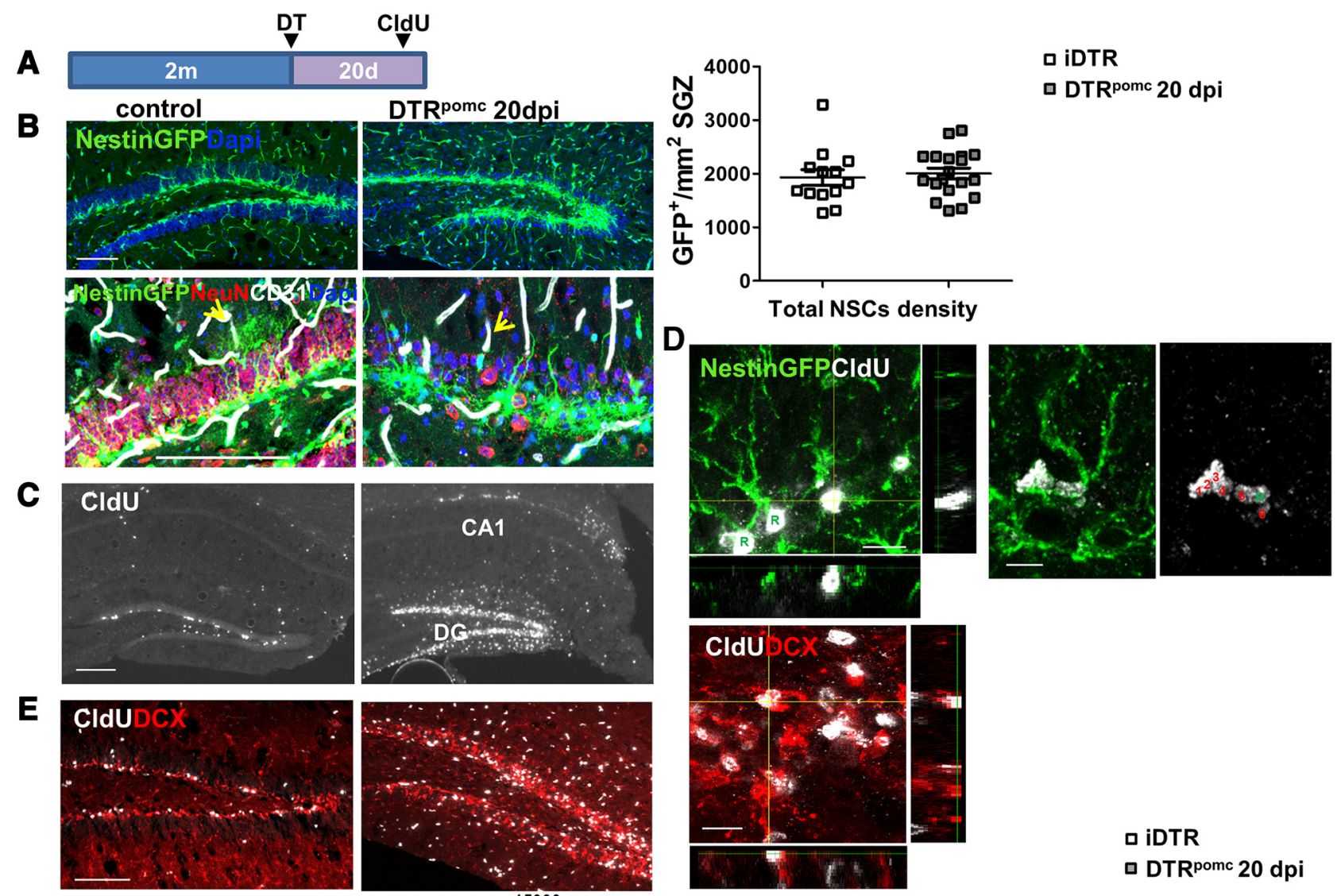

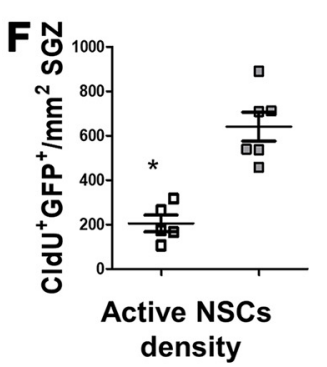

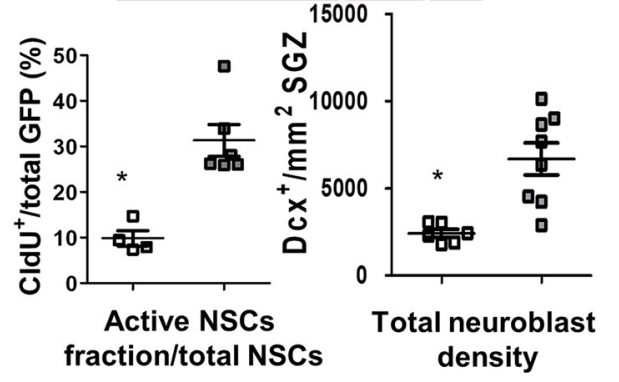

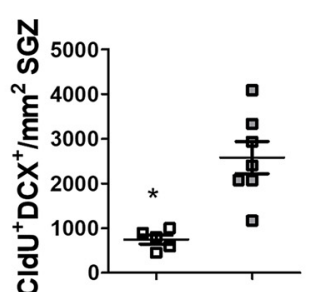

Early neuroblast density

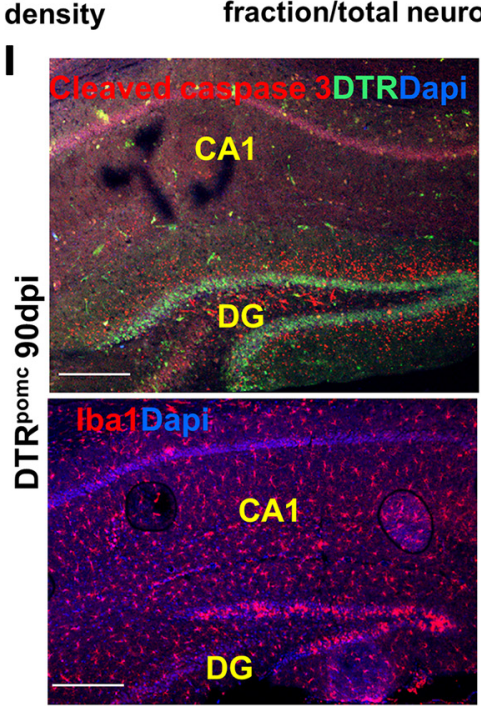

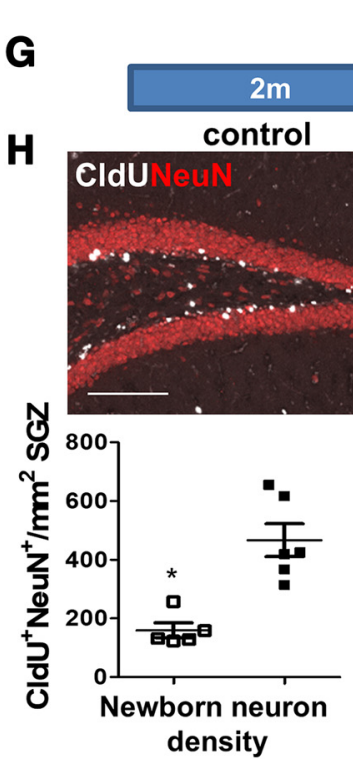

density

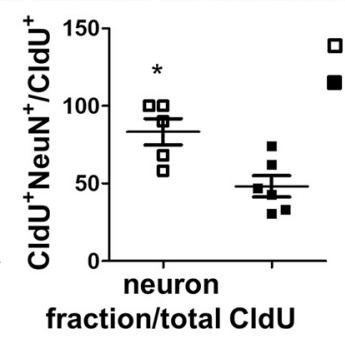

口 IDTR

- DTR ${ }^{\text {pomc }} 90$ dpi

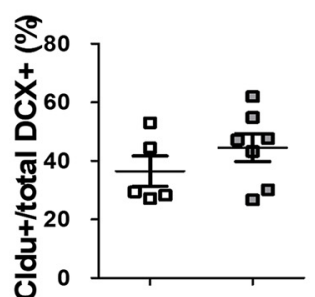

Early neuroblast
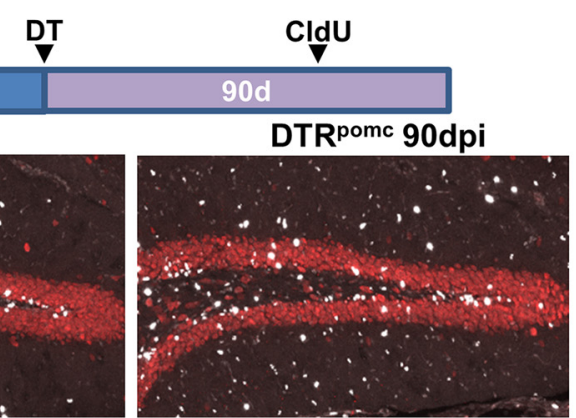

Figure 2. Neurogenesis-driven DG regeneration in DTR ${ }^{\text {pomc }}$ mice. $A$, DT $(3 \mathrm{ng})$ was injected bilaterally to the hippocampus of control iDTR mice or to DTR ${ }^{\text {pomc }}$ mice. Mice also harbored a Nestin-GFP transgene to highlight NSCS. CldU (100 mg/kg 3 intraperitoneal injections every $12 \mathrm{~h}$ ) was injected at $15-16 \mathrm{dpi}$, and brains were retrieved at $20 \mathrm{dpi}$. Relevant for $\boldsymbol{B}-\boldsymbol{F}$. B, RGL-type NSCs highlighted with Nestin-GFP (top) together with $\mathrm{NeuN}^{+}$mature neurons and $\mathrm{CD} 31^{+}$blood vessels at higher magnification (bottom). Note the (Figure legend continues.) 
populations. The extracellular signals were digitized at a sampling rate of $10 \mathrm{kHz}$ and stored by a personal computer using a data acquisition system (Digidata 1322A) and pCLAMP9 software (Molecular Devices). Each focal stimulation was performed 3-5 times, averaged, and the peak amplitude of the population spike was measured (from baseline to peak population spike).

Radial arm water maze (RAWM). This protocol, testing for current working memory, was adapted from previous work (Alamed et al., 2006; Fujisaki et al., 2014). The RAWM apparatus of a circular pool (1 m in diameter) with six 19-cm-wide arms radiating out from the central circular area. Visual cues were included in the test room. The experiment was conducted for 5 consecutive days. Escape transparent Plexiglas platform $(16 \times 16 \times 20 \mathrm{~cm})$ was placed on a different arm each day (the platform location does not change over $1 \mathrm{~d}$ ), forcing the mice to use their memory to solve the task. At the beginning of each acquisition trial, the animal was placed in a different arm out of the remaining arms not containing the escape platform on that day.

During each trial, the animal was allowed to swim into all arms until finding the platform. If during a $1 \mathrm{~min}$ trial the platform was not found, the mouse was gently guided through the water to the platform and was allowed to stay there for $10 \mathrm{~s}$. Thirty minutes after finishing the fourth trial, each animal underwent a fifth trial with the start arm the same as that of Trial 4.

The fifth trial on the fifth day was the "memory retention" trial, in which the number of errors to reach the platform were calculated. Each error was defined as follows: (1) swimming into an arm that does not contain the platform that day (1 error for every wrong arm entrance), (2) entering the goal arm without boarding the platform, or (3) spending $\geq 20$ s continuously in the central zone without any arm selection.

All trails were recorded and analyzed using EthoVision XT10 software (Noldus).

Immunohistochemistry. Brains were fixed by immersion in 4\% PFA for $5 \mathrm{~h}$, incubated in $30 \%$ sucrose, embedded in OCT Tissue-Tec, and cryosectioned to $50 \mu \mathrm{m}$ floating sections. Coronal slices from all aspects of the rostral-caudal axis were examined.

Staining was done as described previously (Licht et al., 2010) with the following: anti-CldU (Serotec, 1:400 PRID:AB_323427), anti-IDU (BD Biosciences, 1:200 PRID:AB_400326), anti-laminin (Neomarkers, 1:400 PRID:AB_60397), anti-doublecortin (DCX) (Millipore, 1:3000 PRID: AB_2230227), anti-CD31 (BD Biosciences, 1:50 PRID:AB_393571), anti-NeuN (Cell Signaling Technology, 1:600 PRID:AB_2630395), antiZnT3 (1:600, \#AZT-013, Alomone Labs), anti-cleaved caspase-3 (1:200, Cell Signaling Technology, PRID:AB_2341188), anti-GFAP (1:500, Dako, PRID: AB_10013482), anti-Ibal (1:200, Wako, PRID:AB_2665520), and anti-HBEGF for DTR (R\&D Systems, 1:200 PRID:AB_354429). Cy5 anti-guinea-pig, $\mathrm{Cy} 5$ anti-rat, $\mathrm{Cy} 2$ and $\mathrm{Cy} 3$ anti-rabbit, and $\mathrm{Cy} 2$ and $\mathrm{Cy} 3$-anti mouse were all obtained from Jackson ImmunoResearch Laboratories (dilution 1:400). Sections were mounted with Permafluor mounting medium (Thermo Fisher Scientific, TA-030-FM) with DAPI (Sigma Millipore, D9542).

(Figure legend continued.) loss of NSC apical processes (arrows) and massive mature neuron deficit in DTR ${ }^{\text {pomc }}$ mice. Scale bar, $100 \mu \mathrm{m}$. Right, Quantification for NSC density revealed no significant change in their numbers. C, CldU immunostaining highlights intensive GCL-specific cell labeling in DTR ${ }^{\text {pomc }}$ DG. Scale bar, $200 \mu \mathrm{m}$. D, CldU immunostaining together with the visualization of GFP ${ }^{+}$cells highlights active NSCs (RGL [R] and descendants). Right, A particular example of a "clone" composed of an RGL (R) and assumed daughter progenitors (labeled 1-6) in DTR ${ }^{\text {pomc }}$. Scale bar, $10 \mu \mathrm{m}$. E, CldU and DCX costaining highlights 4- to 5-d-old early neuroblasts. Right, Representative image in an orthogonal plane showing colocalization of $D C X$ and CIdU. $\boldsymbol{F}$, Quantification of $\boldsymbol{D}$ and $\boldsymbol{E}$. $\boldsymbol{G}$, To allow sufficient time for regeneration, brains were retrieved for analysis $90 \mathrm{~d}$ after injection ( $90 \mathrm{dpi}$ ). $\boldsymbol{H}$, Measurements of differentiation to newly added neurons by $90 \mathrm{dpi}$ were enumerated through CIdU injection 1 month earlier (the time required for newborn neuroblasts to mature) and scoring for double-positive $\mathrm{Cldu}^{+} /$ $\mathrm{NeuN}^{+}$cells in the GCL. Scale bar, $100 \mu \mathrm{m}$. I, Brains of DTR ${ }^{\text {pomc }}$ mice retrieved at $90 \mathrm{dpi}$ and stained for cleaved caspase-3 and for DTR (top) and for microglia (bottom) indicate an ongoing DG toxicity $90 \mathrm{~d}$ from DT injection. Scale bar, $200 \mu \mathrm{m}$. For statistical details, see Table 1. ${ }^{*} p<0.005$.
Confocal microscopy was done using Olympus FV-1000 on $10 \times, 20 \times$, and $60 \times$ lenses and $1.46 \mu \mathrm{m}$ distance between confocal $z$ slices. Lowmagnification images were acquired using Nikon SMZ-25 stereoscope. At least 7 sections per animal from all hippocampal areas at the rostralcaudal axis were counted. Measurements were done using Olympus FV1000 viewer.

DG size quantification. Measurements of the DG were performed as shown in Figure $1 H$. Coronal slices representing all areas of the hippocampus at the anterior-posterior axis were counted. GCL area was measured using X10 NeuN-stained sections by enclosing the GCL (using Olympus, FV-1000 viewer) only in images including the GCL in full. DG height (see Fig. $1 H$, top, yellow) was measured as the distance in micrometers from the dorsal border with stratum lacunosum to the ventral border with the thalamus (yellow line). Measurements were done perpendicular to the center of the dorsal (suprapyramidal) blade. GCL thickness (see Fig. 1H, top, white) was measured at the center of the dorsal blade (white line). Mossy fiber (MF) thickness (see Fig. 1H, bottom) was measured at the dorsal portion of CA3, at the level of the GCL dorsal blade ending (red line). CA1 height (see Fig. 4C) was measured from the dorsal border with the corpus callosum to the ventral border with stratum laconosum, perpendicular to the center of the pyramidal cell layer. Cells in the borders of ROI were included in analysis. All quantifications were done by a blind experimenter.

Cell density quantification. Since the total volume of the GCL was significantly lower in VEGF/DTR ${ }^{\text {pomc }}$ animals, cell numbers were normalized per SGZ area in 3D images, as this parameter did not change significantly in treated animals. The length of the SGZ (inner part of GCL) in every image was measured by Olympus FV-1000 viewer software using the DAPI channel. The area calculation was achieved by multiplying in the number of slices per image (usually 10-15) and the distance between slices $(1.46 \mu \mathrm{m})$. Quantification of cells within this area (DCX, CldU, or IdU) was done manually using the same software by a blind experimenter.

To measure NeuN cell density, we encircled an area of $0.01 \mu \mathrm{m}^{2}$ using Olympus FV-1000 viewer software and counted manually $\mathrm{NeuN}^{+}$cells within the area in a single slice. Cells in the borders of the ROI were included in the analysis in all images.

Microvascular density (MVD) quantification. $Z$ stacks were processed by Bitplane IMARIS 7.6.3 software. An area of $318 \times 318 \times 22.5 \mu \mathrm{m}$, including the hilus, GCL, and molecular layer (ML), was analyzed. Surface function of the channel including blood vessel staining was conducted, and the total volume was measured by IMARIS software (detailed-average values-volume-sum). The ratio between blood vessel volume and the total ROI was calculated.

Experimental design and statistical analysis. Both males and females (from 1 or more litters per experiment) were used. The numbers of animals in each experiment, statistical tests, and statistical values are summarized in Table 1. Graphs include the value per each animal and the mean \pm SEM. Statistical comparisons were computed using SPSS 19.0 software (IBM) and consisted of $t$ tests, one-way, two-way, and repeated-measures ANOVAs, followed by the Tukey post hoc analyses. Before statistical parametric tests, normality and homoscedasticity were assessed using the Shapiro-Wilk test and Levene's Test for Equality of Variances.

\section{Results}

\section{Specific ablation of DG neurons in a diphtheria-toxin-based inducible system}

With the aim of inflicting substantial neuronal loss, specifically of mature GCs, we used DT-based transgenic system in which Cre recombinase activity is driven by a POMC promoter previously shown to be specifically expressed in DG neurons (McHugh et al., 2007). Preparatory experiments using the Ai9 TdTomato reporter validated that, within the brain, $P O M C$-Cre indeed drives expression of the reporter transgene robustly in the DG (for a scheme of transgenes used, see Fig. $1 A$; for results, see Fig. 1B). Because the regenerative capacity of the DG assumedly relies 


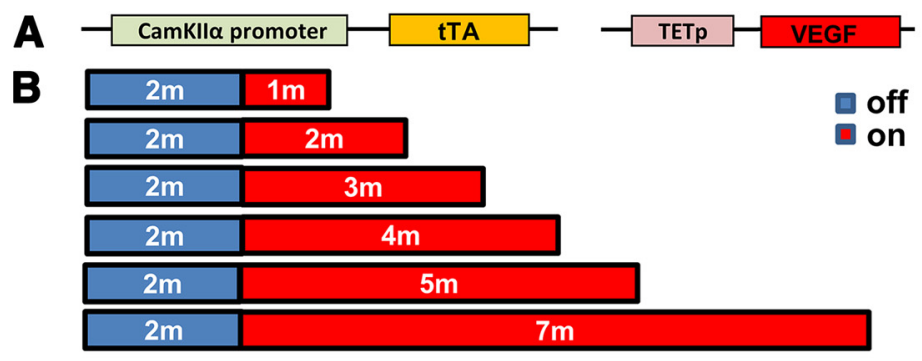

C
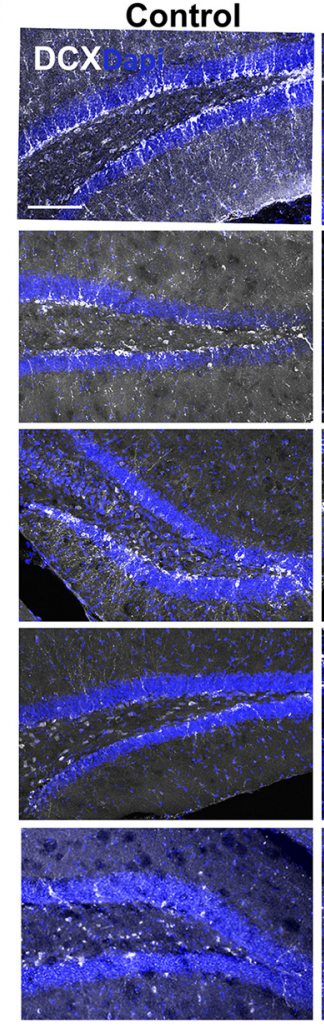
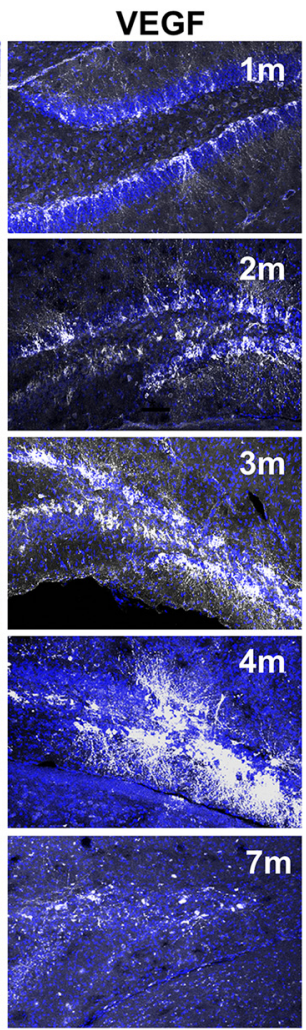

D

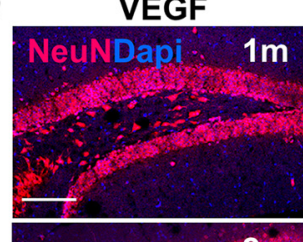

$2 m$

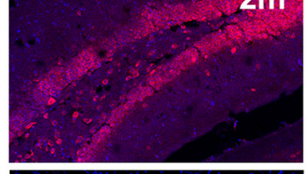

$3 m$
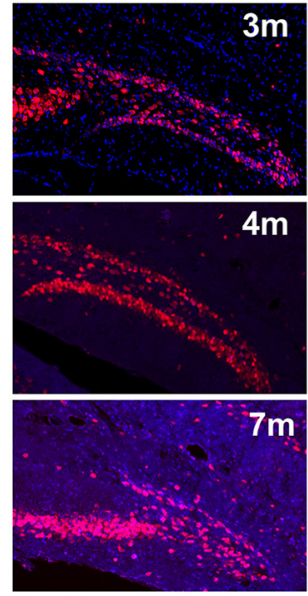

$7 m$

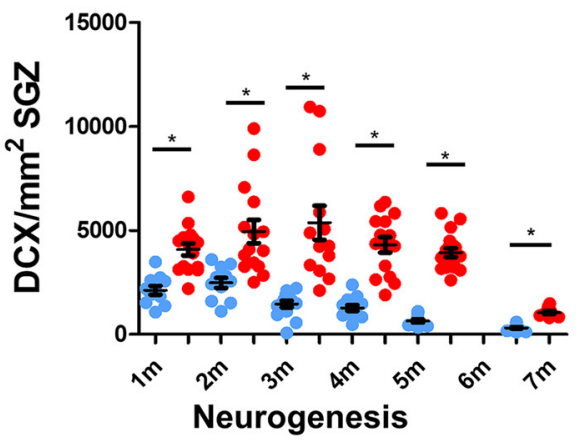

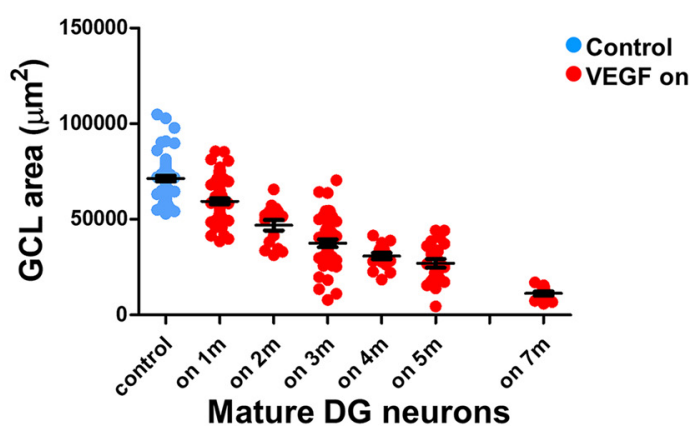

Figure 3. Neurogenesis and DG injury induced by long-term VEGF exposure. $\boldsymbol{A}$, Tetracycline-regulated transgenic system for VEGF expression in the brain. $\boldsymbol{B}$, VEGF was induced (on) in adult (2 months) mice by tetracycline withdrawal and was kept in the on mode for the indicated periods. Littermates harboring only the driver transgene served as controls. $C$, VEGF-induced neurogenesis reflected in an increased number of DCX ${ }^{+}$cells (neuroblasts and immature neurons) in the DG. Bottom, Quantification of DCX ${ }^{+}$cells in the DG in hippocampi removed at the indicated times after VEGF induction. On the contrary to natural neurogenic decline in control mice, an elevated neurogenic rate persists throughout the 7 month period of continuous VEGF exposure. $D$, NeuN staining (labeling mature neurons) highlights dramatic neuronal loss in the DG of prolonged VEGF-expressing animals. Scale bar, $100 \mu \mathrm{m}$. Bottom, Average GCL area measured in NeuN-stained DG sections. For statistical details, see Table $1 .{ }^{*} p<0.005$.

on DG-resident NSCs, it was crucial to show that NSCs will be excluded from $P O M C$-Cre-driven targeted transgenes. Visualizing NSCs with the aid of transgenic Nestin-GFP reporter, known to highlight radial glia-like (RGL) NSCs (Mignone et al., 2004), confirmed that this was indeed the case (Fig. 1B, right). Costaining hippocampal sections for DCX to highlight differentiated neuroblasts showed that neuroblasts are also negative for Ai9 TdTomato (Fig. 1C), thereby securing that, unlike previously used DT-based neuronal ablation system causing widespread neuronal death (Yamasaki et al., 2007; Myczek et al., 2014), only mature GCs would be subjected to ablation with the aid of POMC-driven Cre recombinase. 
A

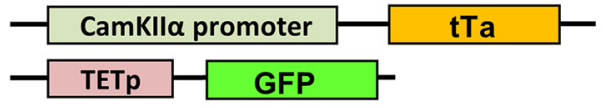

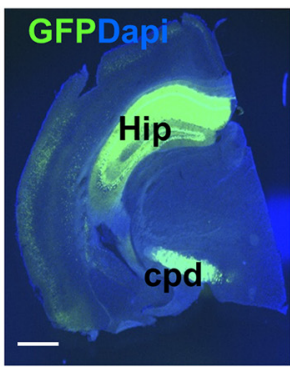

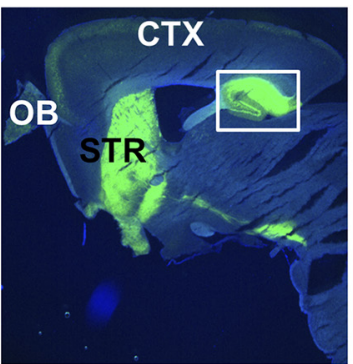

DG

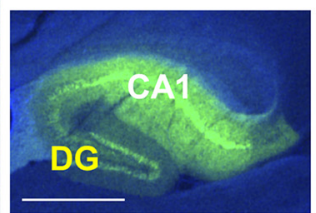

Control - VEGF 4m

B
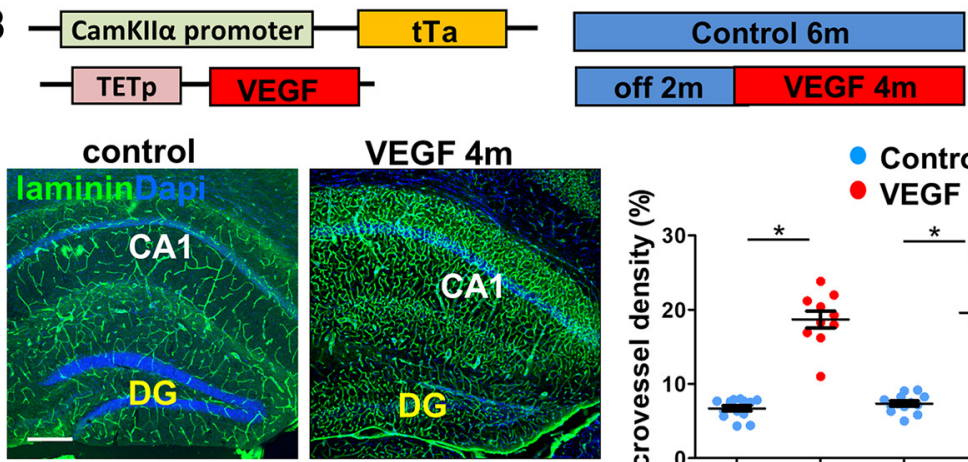

tTa \begin{tabular}{l|l} 
off $2 m$ & VEGF $4 m$
\end{tabular}
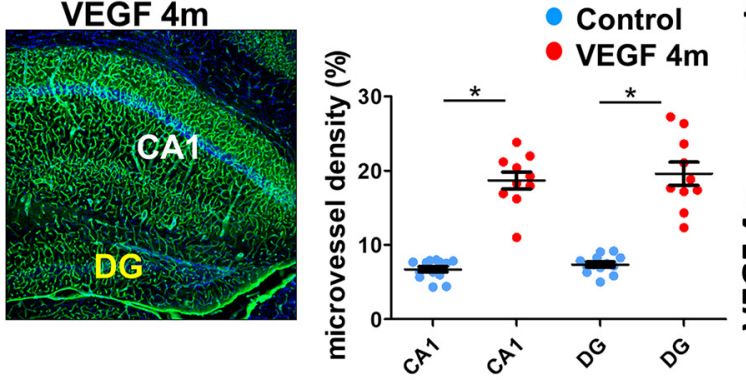

C
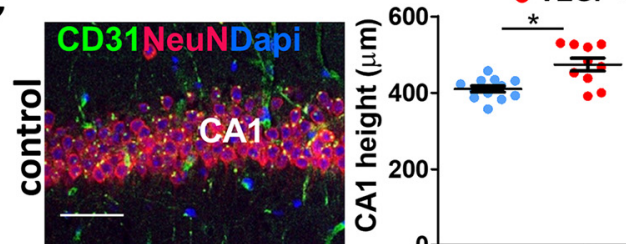

D

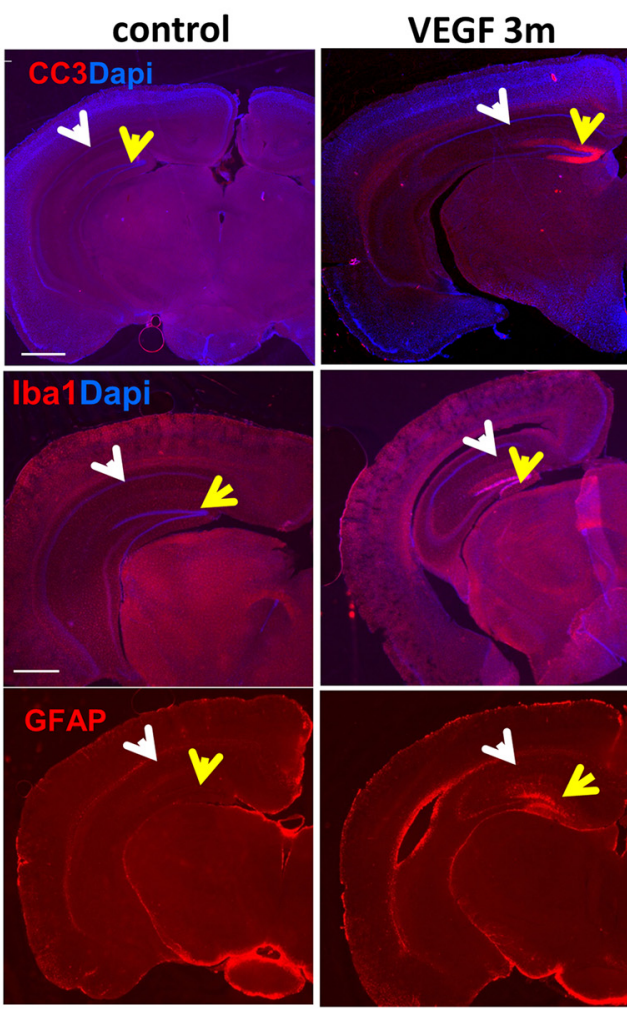

E
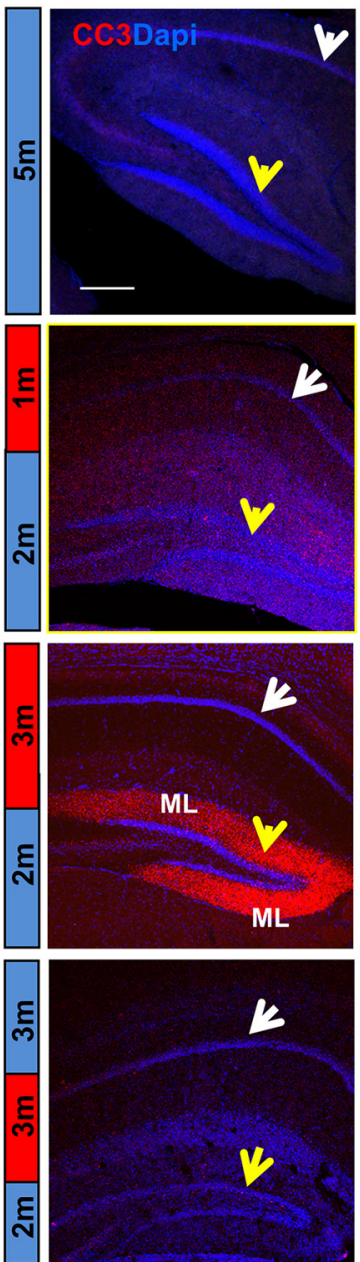
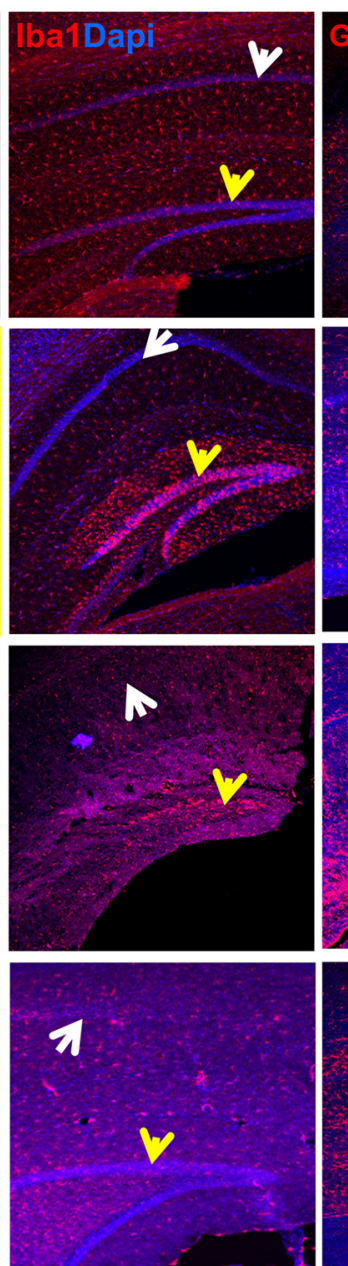
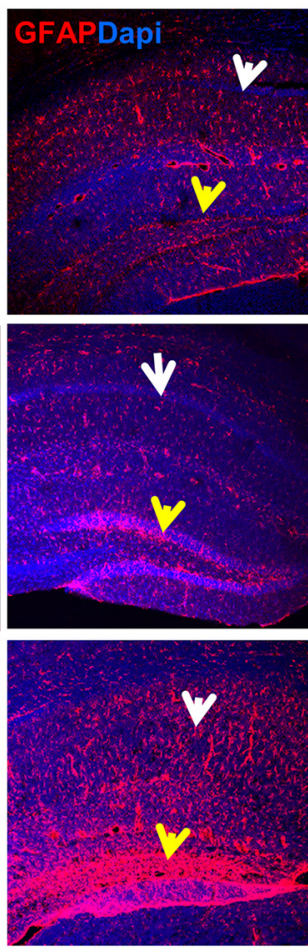

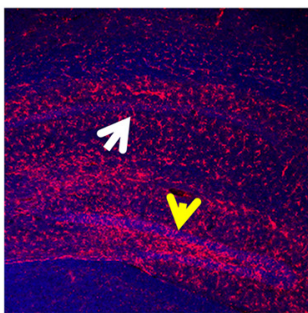

Figure 4. Global long-term VEGF overexpression induces DG-specific injury. A, CaMKII $\alpha$-tTA mouse was crossed to the Tet-GFP responder line to highlight which areas are affected by the transgenic system. GFP in coronal (left) and sagittal (middle) sections is mainly expressed in the hippocampus (Hip), the cerebral peduncles (cpd), and the striatum (STR) and, to a lesser extent, in the cortex (CTX) and olfactory bulb (OB). Within the hippocampus, GFP expression is stronger in the CA1 (right). Scale bar, 1 mm. $\boldsymbol{B}$, Adult (2 months) (Figure legend continues.) 
To ablate GCs, $P O M C$-Cre mice were crossed to mice harboring a Cre-inducible DT receptor (iDTR) transgene (Fig. $1 D$ ) and double-transgenic mice (dubbed $\mathrm{DTR}^{\text {pomc }}$ mice) were challenged with DT using unilateral intrahippocampal stereotactic DT injection. Massive death of DG neurons was evidenced already by $5 \mathrm{~d}$ after DT injection ( $5 \mathrm{dpi})$, marked by DG-specific immunoreactivity for cleaved caspase-3. Noteworthy, cleaved caspase-3 was not only detected in GC cell bodies but mostly in their dendrites extending to the adjacent ML (Fig. 1E, left). Apparent clustering of microglia in the GCL provided additional, indirect evidence for DG-specific cell damage (Fig. $1 E$, right).

The magnitude of the neuronal deficit was evaluated at $20 \mathrm{dpi}$ where a marked reduction in overall DG cellularity was evident and calculated to comprise more than half of DG neurons (Fig. $1 F$, left, middle; for quantification, see Fig. $1 H$ ). MF, the axonal tract extended by GCs, highlighted by immunostaining for the zinc transporter ZnT3 (Palmiter et al., 1996), was also greatly reduced (Fig. 1G,H).

\section{DG-resident NSCs drive full regain of lost neurons}

The DT-based system of selective GC ablation described above provided us with a suitable platform for examining whether, and to what extent, the DG can recover from such massive damage. To determine whether the substantial neuronal loss evidenced at $20 \mathrm{dpi}$ can be repaired, and to allow sufficient time for regeneration, DT-treated brains of littermate mice were retrieved for analysis $70 \mathrm{~d}$ later (i.e., at $90 \mathrm{dpi}$ ). Remarkably, the neuronal deficit was found to be nearly fully rectified and the intact DG cellularity restored. This was evidenced in the restoration of normal DG height, GCL thickness, recovery of the $\mathrm{MF}$, and regaining the initial number of NeuN-positive DG neurons (Fig. $1 F-H$ ).

To determine whether this regenerative capacity is driven by resident NSCs, brains were retrieved for analysis at 20 dpi (Fig. $2 A$ ), that is, the time point where substantial neuronal loss has already taken place and regeneration is ongoing. The assumption that NSCs will be spared in DT-injected DTR ${ }^{\text {pomc }}$ mice was validated by the observation that, despite a massive DG neuronal loss, the number of Nestin-GFP ${ }^{+}$NSCs was not reduced (Fig. $2 B$ ). Morphologically, RGL-type NSCs in DTR ${ }^{\text {pomc }}$ mice appeared to possess a major apical shaft and to lose the fine tree-like apical processes, a configuration previously shown to represent a reactive NSC morphology (Sierra et al., 2015; Licht et al., 2016) (Fig. 2B, bottom). To follow the fate of dividing cells, the thymi-

\footnotetext{
$\leftarrow$

(Figure legend continued.) CaMKII $\alpha$ - TTA tet-VEGF mice were subjected to VEGF induction for 4 months. VEGF-induced angiogenesis reflected in MVD increase in both DG and CA1 regions of the hippocampus. Left, Blood vessels highlighted by laminin immunostaining. Scale bar, 200 $\mu \mathrm{m}$. Note DG-selective degeneration in the 4 month VEGF mouse. Right, MVD quantification in the respective hippocampal region showing equal angiogenic responsiveness to VEGF in both areas. $\boldsymbol{C}$, The CA1 area of the same mice as in $\boldsymbol{B}$ was immunostained for CD31 and NeuN. Scale bar, $50 \mu \mathrm{m}$. Right, quantification. The height of CA1 in VEGF animals is slightly larger than control animals, a potential reflection of extensive blood vessel formation. $\boldsymbol{D}$, Lowmagnification images of the whole brain to highlight $D G$ selectivity of the detrimental response to VEGF. Immunostaining for cleaved caspase 3 (CC3), Iba1 for microglia, and GFAP for astrocytes is shown. White arrows indicate CA1. Yellow arrows indicate DG. Scale bars, $1 \mathrm{~mm}$. $\boldsymbol{E}$, High-magnification images of $\mathrm{CC} 3, \mathrm{Iba} 1$, and GFAP in control animals, 1 month VEGF induction, 3 month VEGF induction, and following additional 3 months of VEGF withdrawal (VEGF on $>$ off). White arrows indicate (A1. Yellow arrows indicate DG. Similarly to the DTR ${ }^{\text {pomc }}$ model, the majority of cleaved caspase 3 is localized in the ML of the DG. Scale bars, $200 \mu \mathrm{m}$. For statistical details, see Table $1 .{ }^{*} p<0.005$.
}

dine analog $\mathrm{CldU}$ was injected at $15-16$ dpi (i.e., $4-5 \mathrm{~d}$ before brain retrieval). Intensive cell labeling was detected in the GCL of $\mathrm{DTR}^{\mathrm{pomc}}$ mice compared with the low basal neurogenic level observed in control mice (Fig. 2C). A significant fraction of NSCs was labeled with CldU (cells identified as $\mathrm{GFP}^{+} / \mathrm{CldU}^{+}$) (Fig. $2 D, F)$. Further support to the contention that regeneration is driven by local NSCs comes from the observation of discernible "clones" composed of progenitors (cells with no radial shaft) clustered around a proliferating RGL-type NSC, all positive for CldU (Fig. $2 D$, right). The total number of $\mathrm{DCX}^{+}$neuroblasts, as well as the number of early neuroblasts (colabeled with CldU), were also higher in DTR ${ }^{\text {pomc }}$ mice (Fig. $2 E, F$ ). Active neuroblasts appeared to lose their typical morphology and to cluster at aberrant locales (Fig. 2E), as was shown for epilepsy models (Jessberger et al., 2007). To show that neuroblasts eventually differentiate into mature neurons, CldU was pulse-labeled at 60 dpi and $\mathrm{CldU}^{+} / \mathrm{NeuN}^{+}$mature neurons were enumerated at 90 dpi (Fig. 2G). Results confirmed a dramatic increase in newly added mature neurons in the regenerated DG (Fig. $2 \mathrm{H}$ ). Together, these findings attest to the ability of DG NSCs to drive full recovery of the DG following a massive injury. It should be noted, however, that even though normal cellularity was achieved at 90 dpi, cleaved caspase 3 and activated microglia were still evident in the DG, indicative of ongoing injury (Fig. 2I). We therefore sought an additional system where the damage and regeneration phases are completely uncoupled.

\section{Inflicting DG-specific neuronal loss by long-term exposure to ectopic VEGF}

To corroborate that the DG can recover from extensive damage associated with massive neuronal loss, we examined its regenerative potential following a DG-specific injury of a different nature.

To this end, we used a transgenic platform allowing for brainspecific induction of ectopic VEGF in a conditional and reversible manner. Briefly, the system used was a bitransgenic mouse system composed of a tetracycline-regulated, CamkII $\alpha$ promotertrans-activator (CamkII $\alpha-t T A)$ "driving" transgene (Mayford et al., 1996) and a tet-VEGF 165 "responder" transgene (Fig. 3A). This system was previously used by us to uncover a role for VEGF in reversible modulations of neuronal plasticity (Licht et al., 2011) and a role in the enhancement of adult hippocampal neurogenesis (Licht et al., 2016), but was later found to be associated with a substantial DG-specific damage whenever ectopic VEGF overexpression continued for a period exceeding 2 months. In our previous studies, VEGF was induced for up to 1 month, a period proven sufficient for eliciting sustained neurogenic enhancement, and then deinduced, conditions under which no hippocampal damage could be detected (Licht et al., 2016).

Here, VEGF induction was extended for a period of several months, conditions under which excessive VEGF led to not only angiogenic and neurogenic responses but was also associated with substantial selective DG damage underscoring the exceptional vulnerability of the DG (see below).

\section{The nature and selectivity of DG injury}

To evaluate the magnitude of VEGF-induced damage, VEGF was induced in mature 2-month-old CamkII $\alpha$-tTA: tet-VEGF double-transgenic mice and continuously kept in the VEGF-ON mode. Brains retrieved at monthly intervals (Fig. $3 B$ ) were sectioned and immunostained for the neuroblast marker DCX (Fig. $3 C$ ) and for the pan-neuronal marker NeuN (Fig. 3D). Results showed an enhanced neurogenic response that persists for several 
A
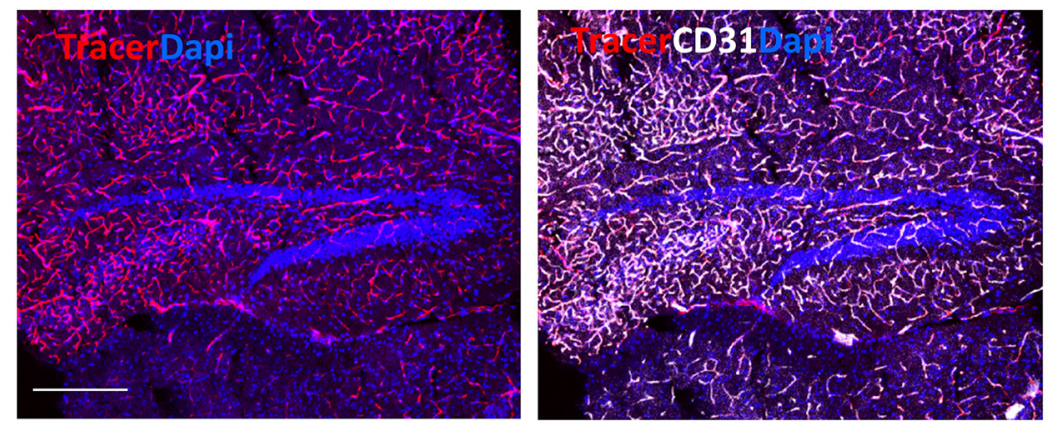

B

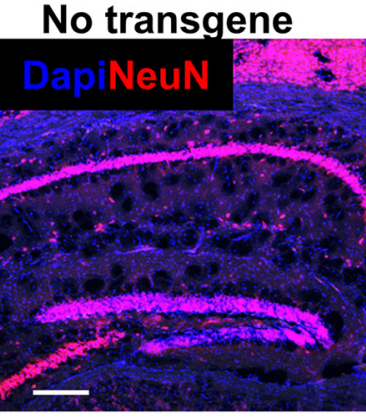

C
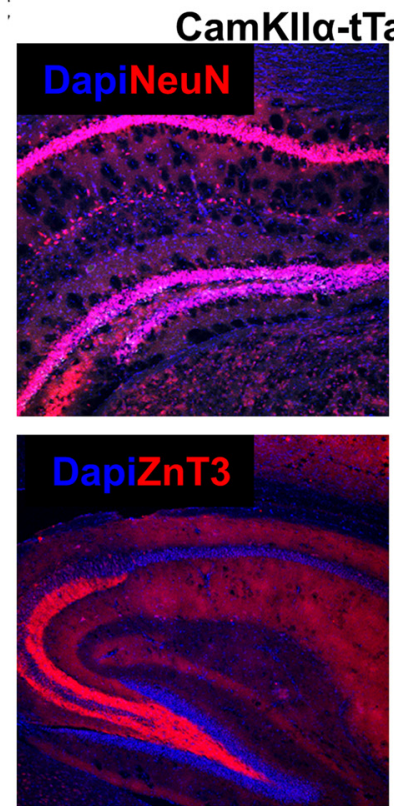

E

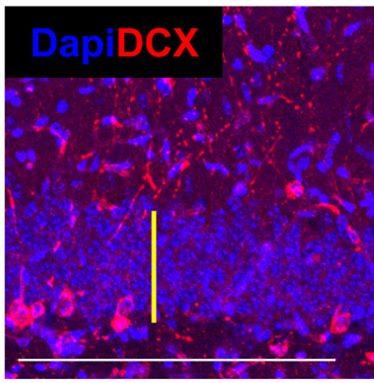

Empty AAV vector
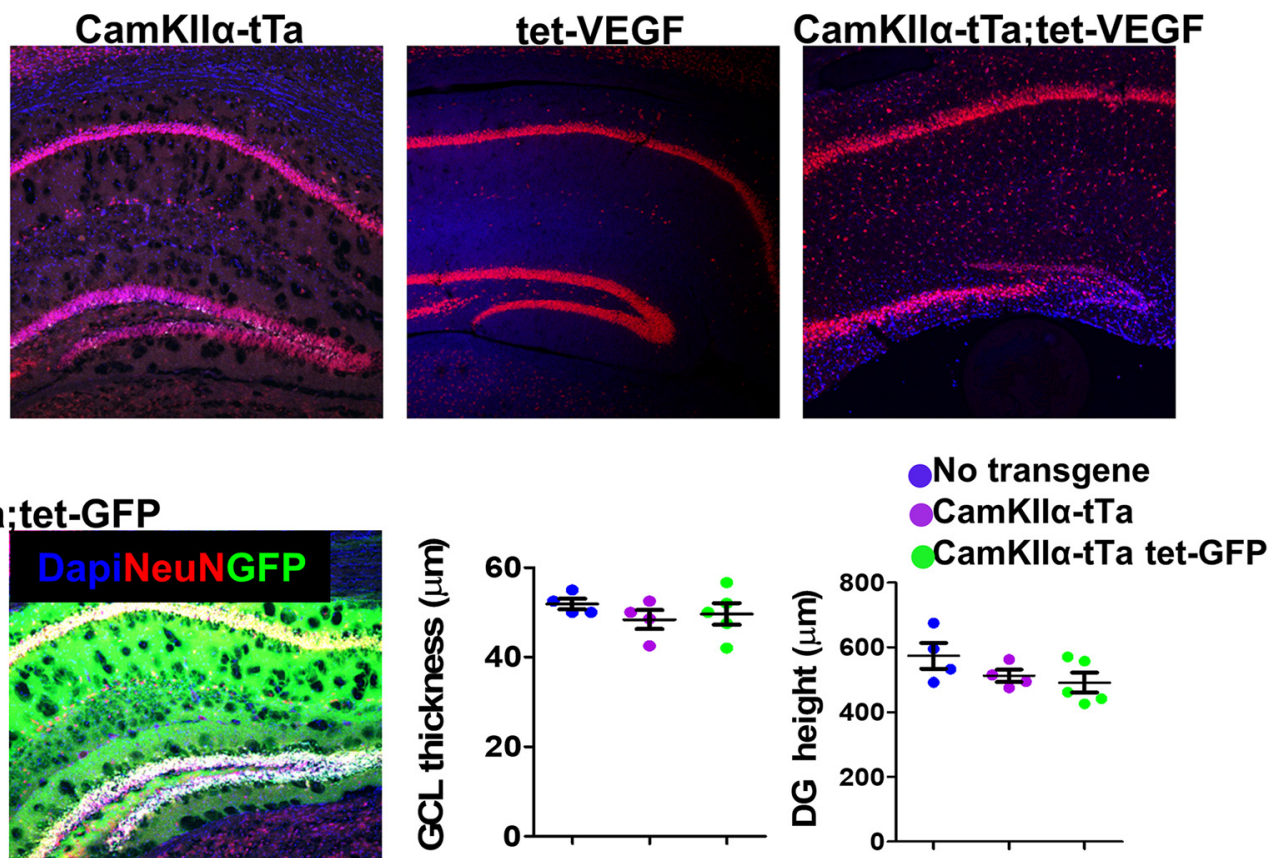

D
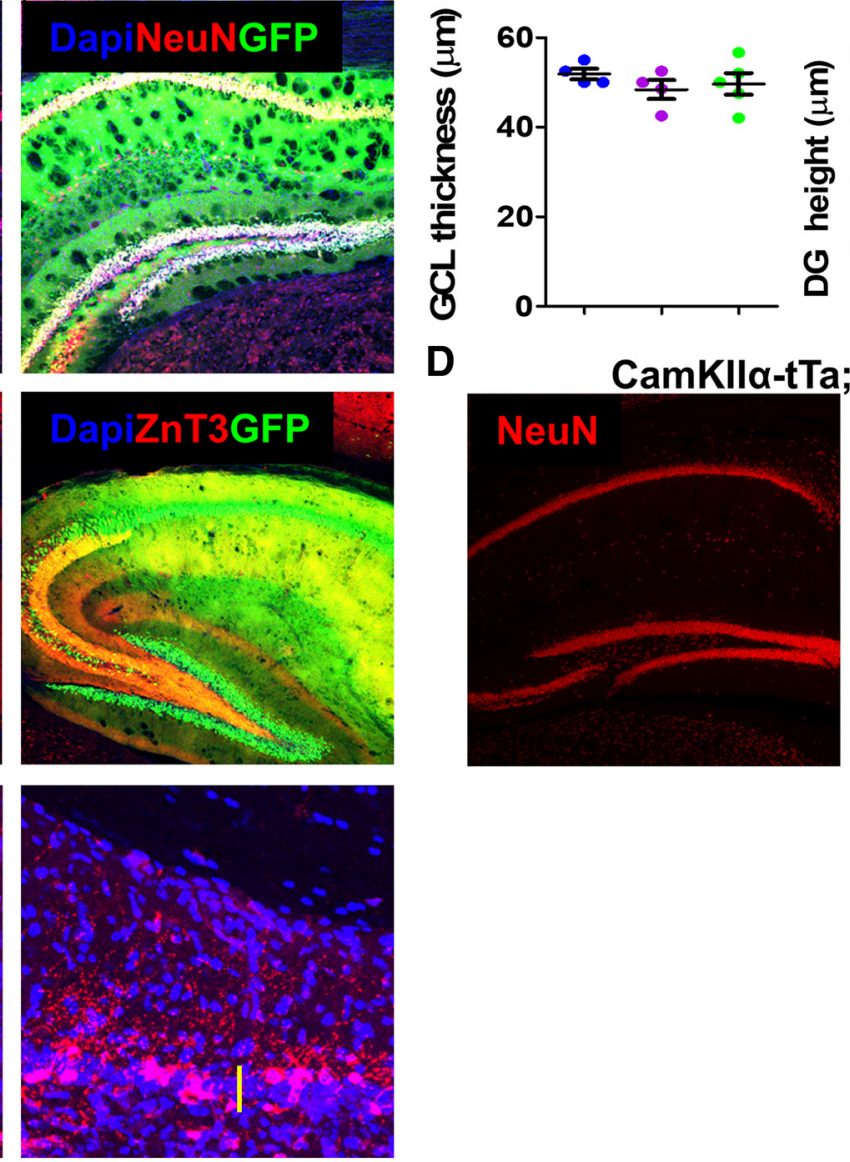

\section{AAV VEGF}

Figure 5. Precluding potential mechanisms for DG-specific damage in the Camkll $\alpha$-tTA;tet-VEGF mouse model. $A$, To test for DG-specific changes in permeability following VEGF induction, TRITC-labeled $10 \mathrm{kDa}$ dextran (tracer) was injected intracardially 2 min before death. Costaining with CD31 for endothelial cells demonstrates that dextran labeling is limited to the endothelial lumen. $\boldsymbol{B}-\boldsymbol{D}$, Camkll $\alpha$-tTA mouse line-related toxicity. $\boldsymbol{B}$, NeuN-stained hippocampal slices of 6-month-old mice (from the same litter) are presented. The genotype of each animal is indicated above. Tetracycline was replaced by water at the age of 2 months in all mice. C, Camkll $\alpha$-tTA driver line was crossed to a tet-GFP responder line. Tetracycline was omitted from drinking water at the age of 2-6 months. Intact MF axon indicated by ZnT3 staining. Quantification of DG height and GCL thickness is presented. No significance was found. (Figure legend continues.) 
months (when natural neurogenesis subsided with age) and ceased only by 7 months from the onset of VEGF overexpression (Fig. 3C). Concomitantly, there was a substantial, progressive reduction in the number of detectable mature DG neurons (Fig. $3 D)$.

We wished to examine whether the detrimental response to VEGF is region-specific. With the aid of tet-GFP responder mouse (Fig. $4 A$ ), we aimed to examine the expression pattern dictated by the CaMKII $\alpha$ - $t$ TA driver line. We were able to demonstrate a higher GFP expression in the CA1 in comparison with the DG (right). Similarly, using the TET-VEGF as a responder line (induced for 4 months), we showed that endothelial cells of the CA1 and the DG were equally responsive to VEGF, as judged by a comparable angiogenic response elicited by VEGF in both DG and CA1 (Fig. 4B). However, only the former showed clear evidence of neuronal damage due to the observation that the CA1 pyramidal cell density and height did not decrease (Fig. 4C). These findings reinforce the notion of exceptional DG vulnerability compared with other regions of the hippocampus. A further indication for the DG-specific VEGF-induced toxicity was apparent DG-restricted caspase-3 activation (Fig. 4D, top, shown for the whole brain) and, indirectly, also DG-specific astrogliosis and microgliosis manifested in clustering of astrocytes and microglia in the injured DG but not in the CA1 (Fig. 4D, middle, bottom). The kinetics of activation cleaved caspase-3, astrocytes, and microglia after 1 and 3 months of VEGF induction are presented in Figure $4 E$. While caspase 3 and astrocytes are highly activated only at 3 months from VEGF induction, microglia are activated at an earlier time point. Active microglia populate the DG specifically, as early as $3 \mathrm{~d}$ from VEGF induction (Kreisel et al., 2019) and may serve as the trigger for the selective response of the DG to VEGF.

VEGF is known as a neuroprotective agent (Jin et al., 2000; Oosthuyse et al., 2001). Here we show that, under certain conditions, VEGF could become neurotoxic. The mechanism for GCselective neurotoxicity is not clear. The possibility that DG degeneration is secondary to excessive VEGF-induced vascular leakage was ruled out this option by showing that blood vessels in the DG are not leaky (Fig. 5A). Likewise, the possibility that the CamkII $\alpha$-tTA transgene used may on its own induce DG degeneration (Sirerol-Piquer et al., 2011; Han et al., 2012; Melnikova et al., 2016; Watanabe et al., 2016; Kukreja et al., 2018) was ruled out by showing that without the VEGFresponder transgene no damage was incurred (Fig. 5B-D). Also, DG degeneration and enhanced ectopic neurogenesis were reproduced using intrahippocampal injection of VEGFencoding AAV (Fig. 5E).

\section{Regain of normal DG cellularity and morphological features following VEGF withdrawal}

In light of our findings that DG regeneration in the DT model relies on NSC-driven neurogenesis (Fig. 2), together with findings that DG neurogenesis in rodents precipitously declines with

\section{$\leftarrow$}

(Figure legend continued.) $\quad$ D, Camkll $\alpha$-tTA driver line was crossed to a tet-hsVEGFR1 line. This mouse line expresses inducible soluble human VEGF receptor 1 that serves as a "VEGF trap" (Licht et al., 2010). Tetracycline was replaced by water from embryonic day 14.5 to 6 months postnatally. $\boldsymbol{E}$, Intrahippocampal injection of AAV encoding VEGF induces DG damage, which is similar to transgenically induced VEGF. DCX immunostaining is shown. Note the reduction in GCL thickness (yellow bars) and ectopic neurogenesis. Scale bars, $200 \mu \mathrm{m}$. For statistical details, see Table 1. age (Ben Abdallah et al., 2010; Encinas et al., 2011), the time point of 3 months after VEGF induction was selected as the "baseline" for repair (Fig. 6). As in the DTR ${ }^{\text {pomc }}$ model, neuronal loss was measured as reduced GCL thickness, reduced density of $\mathrm{NeuN}^{+}$ neurons, DG height (which includes also the space occupied by GC dendrites and axons), and MF thickness. Three months after continual VEGF exposure, GCL thickness was reduced by $>60 \%$ and the density of GCL cell bodies and the total height of the DG by $40 \%$ (Fig. $6 B, D$ ). The thickness of the MF layer (visualized by ZnT3 immunostaining) was also dramatically reduced (Fig. $6 C, D)$.

To examine the regenerative potential of the injured DG, the damaging insult was terminated by "switching-off" VEGF (readdition of tetracycline to the drinking water). On the basis of our previous studies showing that VEGF levels in brain parenchyma return to basal low levels within a couple of weeks from tetracycline addition (Licht et al., 2011), and to allow sufficient time for regeneration, brains were retrieved for analysis 3 months after VEGF deinduction (on>off; Fig. 6A). As shown in Figure $6 B-D$, the neuronal deficit was repaired in the majority of animals in this timeframe and normal DG cellularity was nearly fully regained. MF, barely detectable in the injured DG, was found to be restored in many (but not all) cases (Fig. $6 C, D)$. The magnitude of recovery was assessed by measuring the GCL area in NeuN-stained sections at different time points during recovery. The graph presented in Figure $3 D$ is shown again with the on $>$ off group (Fig. $6 E$ ). All damage-associated markers (e.g., cleaved caspase 3, active microglia, and astrogliosis) were barely detected after 3 months of VEGF withdrawal (Fig. 4E, bottom).

\section{Changes in neurogenesis rate and differentiation during degeneration and regeneration}

VEGF-induced neurogenesis during degeneration (3 months on) and regeneration ( 3 months on $/ 2$ months off) was examined at the level of NSCs with the aid of Nestin-GFP mice. IdU was injected 1-2 d before brain retrieval (Fig. 7A). While the total numbers of NSCs were slightly reduced in the degenerated DG (Fig. $7 B, D$, left), the numbers of active $\left(\mathrm{IdU}^{+}\right)$NSCs were significantly higher in both on and on $>$ off groups (Fig. 7C,D). In the control DG, NSCs appear as typical tree-like cells and their apical processes are associated with blood vessels (Fig. $7 B$, bottom) (for further data for NSC-BV association, see Licht and Keshet, 2015; Moss et al., 2016). In both on and on $>$ off groups, NSCs acquire a modified morphology, lose the majority of the apical fine processes (their apical major shaft still in contact with blood vessels) (Fig. $7 B$, insets, $C$ ), and also send some cellular projections into the hilus (Fig. $7 C$ ). Modification of NSC morphology was reported earlier to be associated with kainic acid treatment (reactive-type NSCs) (Sierra et al., 2015).

To reconcile the seemingly paradoxical situation of a higher rate of neuroblast production and yet progressive decrease in the number of mature DG neurons, we measured the fraction of newborn neuroblasts eventually differentiating into mature neurons. To this end, 3 months from the onset of VEGF induction mice were pulse-labeled with CldU and killed 3 weeks thereafter to allow sufficient time for newborn neuroblasts to differentiate into mature $\mathrm{NeuN}^{+}$neurons (Fig. $\left.8 A, B\right)$. Unlike a higher $(\sim 5$ fold) rate of NSCs divisions (Fig. 7D) and similar increase in neuroblast production $\left(\mathrm{DCX}^{+}\right.$cells; Fig. $\left.8 \mathrm{C}\right)$, the number of newly added mature neurons was marginal (1.37-fold more $\mathrm{CldU}^{+} / \mathrm{NeuN}^{+}$cells in 3 months on mice; Fig. $8 \mathrm{~B}$ ), suggestive of 

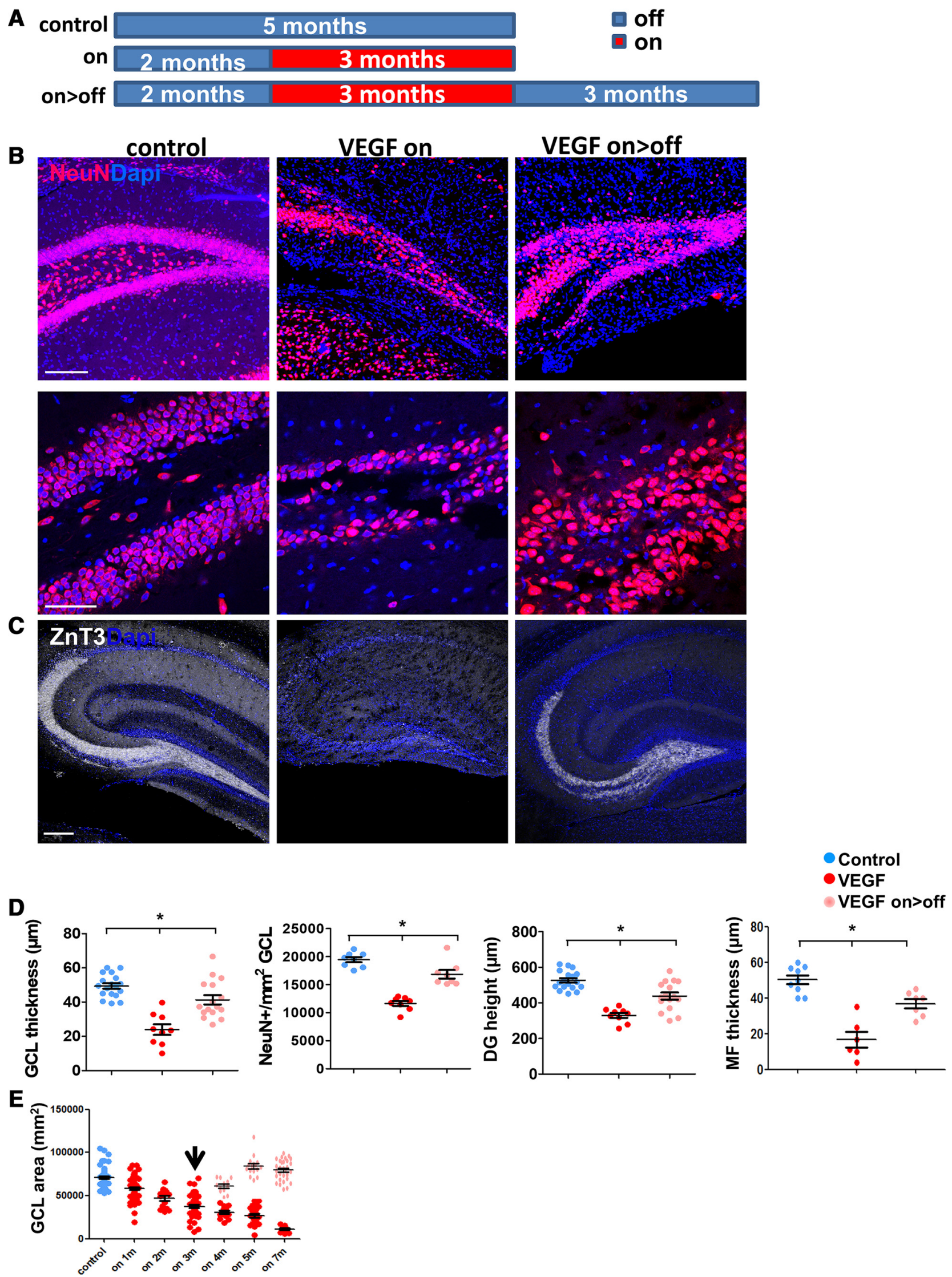

Figure 6. The injury to the DG following long-term VEGF exposure is rectified upon VEGF deinduction. $A$, Experimental protocol: off group, monotransgenic littermates killed at 5 months; on group, VEGF induced at the age of 2 months and brains retrieved at 5 months; on $>$ off group, VEGF induced at 2 months, deinduced at 5 months, and killed at 8 months (on $>$ off). $\boldsymbol{B}$, NeuN-immunostained DG sections showing a marked neuronal deficit in VEGF on mice and neuronal regain 3 months after VEGF deinduction. Scale bars: top, $200 \mu \mathrm{m} ;$ bottom, $50 \mu \mathrm{m}$. $C$, ZnT3-stained sections highlighting MF axon of GCS. Scale bar, $100 \mu \mathrm{m}$. D, Quantification of DG measurements as above indicative of neuronal cell loss and of neuronal (Figure legend continues.) 
A

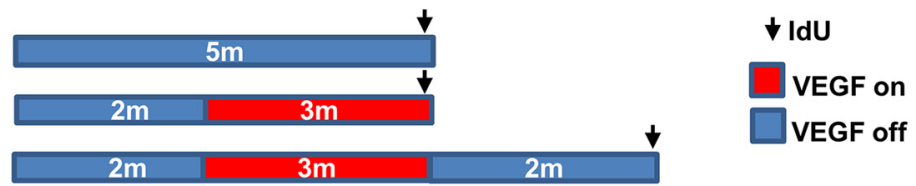

B
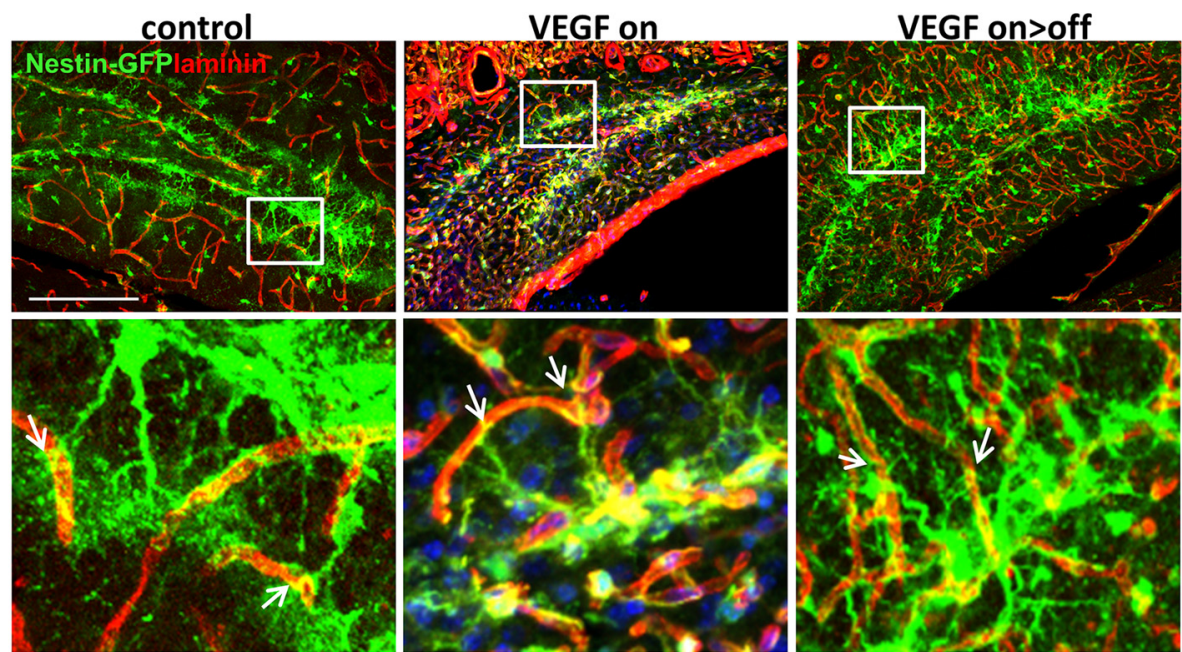

C
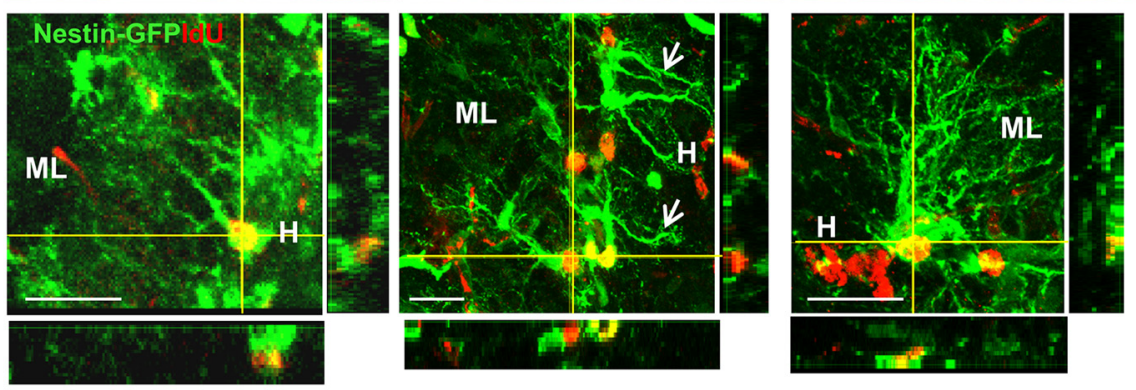

D

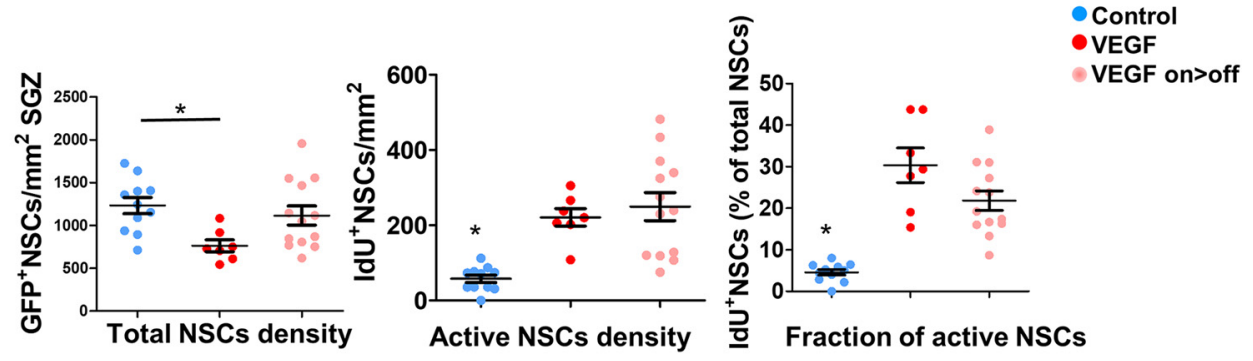

Figure 7. NSC proliferation during DG degeneration and recovery. A, Nestin-GFP transgenic mice were crossed to the VEGF transgenic system. VEGF was induced for 3 months followed by deinduction for an additional 3 months. IdU (100 mg/kg i.p.) was applied 1-2 d before brain retrieval. B, Slices were coimmunostained for GFP and for laminin to highlight blood vessels. Scale bar, $200 \mu \mathrm{m}$. Note contact points of NSCs' apical processes with blood vessels (arrows). C, GFP and IdU immunostaining. Scale bar, $20 \mu \mathrm{m}$. H, Hilus; ML- molecular layer. Note hilar projections of NSCs in VEGF on animal (Arrows). $D$, The total numbers of GFP ${ }^{+} \mathrm{NSC}$ and the fraction of dividing NSCS (IdU ${ }^{+}$) are quantified. A significant increase in NSC proliferation in both on and on $>$off groups overrides expected NSC exhaustion. For statistical details, see Table $1 .{ }^{*} p<0.0002$.

nonproductive neurogenesis in which only a minor fraction of neuroblasts eventually mature. Another indication of aberrant neurogenesis was that resembling the situation in epilepsy models (Jessberger et al., 2007; Cho et al., 2015), DCX ${ }^{+}$cells were found in ectopic locations, such as in the inner $\mathrm{ML}$ and the hilus (Fig. 8C, insets). Interestingly, neurogenesis during the repair phase continued at the same high rate observed before VEGF

(Figure legend continued.) regain (although not the reaching same values of control). $\boldsymbol{E}$, Quantification of GCL area (using NeuN-stained sections) as in Figure 3D, with the addition of the on $<$ off group. Arrow indicates time of tetracycline supplementation for the on $>$ off groups. For statistical details, see Table $1 .{ }^{*} p=0.00005$. deinduction, quantified through enumeration of both proliferating NSCs and DCX ${ }^{+}$neuroblasts as fourfold higher than neurogenesis in noninjured littermate controls (Fig. $7 D$ and Fig. $8 C$, respectively). However, unlike nonproductive neurogenesis under prolonged, ongoing VEGF overexpression, neuroblasts generated during the repair period survived and successfully differentiated to mature $\mathrm{NeuN}^{+}$neurons. This was evidenced in $\mathrm{a} \sim 4$-fold increase of $\mathrm{CldU}^{+} \mathrm{NeuN}^{+}$cells compared with control or VEGF-on animals (Fig. $8 B$ ).

We measured the numbers of 3 -week-old DCX cells $\left(\mathrm{CldU}^{+} \mathrm{DCX}^{+}\right)$, a population of late neuroblasts entering the final step of differentiation (Fig. 8D). This population was proportional to the total numbers of DCX cells in all groups, leading 

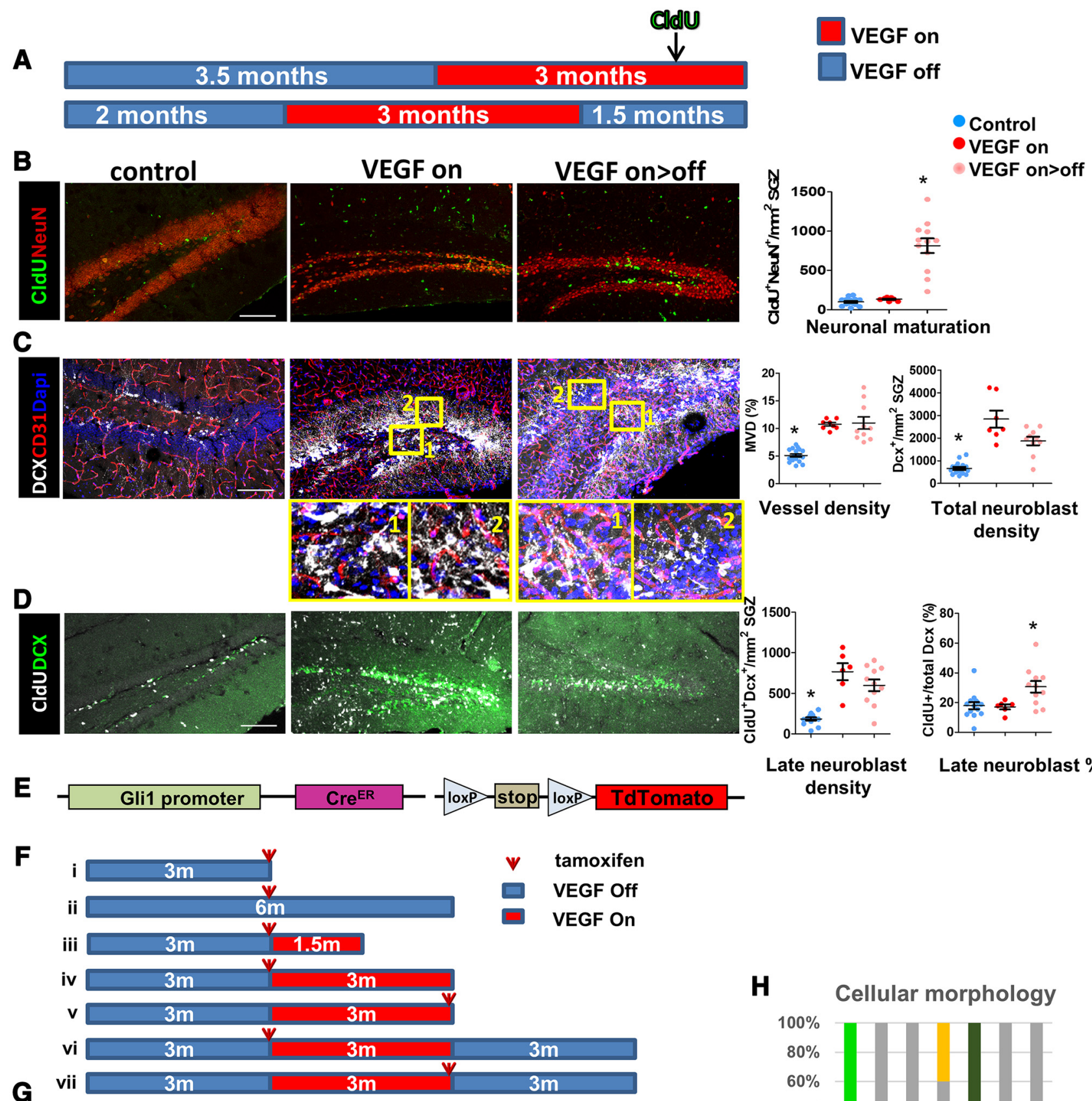

Late neuroblast Late neuroblast \% density
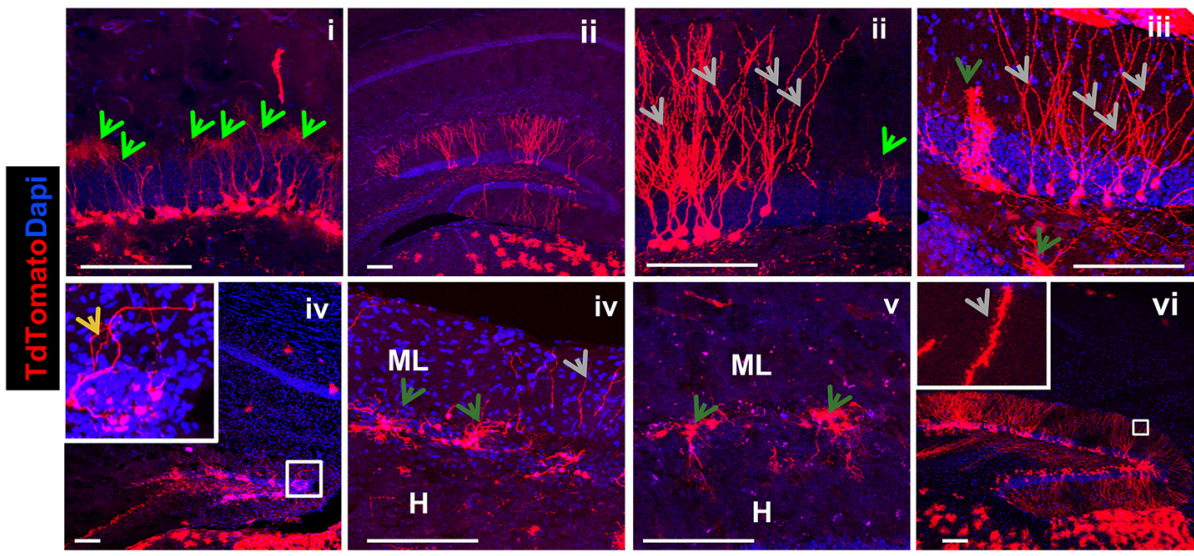

H Cellular morphology
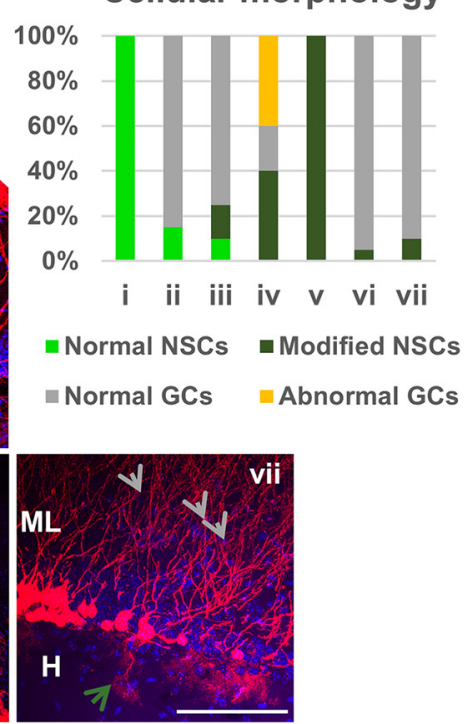

Figure 8. Differentiation and maturation of $D G$ newborn cells during degeneration and regeneration. $\boldsymbol{A}$, Schedules of VEGF induction and, in turn, deinduction relevant to $\boldsymbol{B}-\boldsymbol{D}$. CldU was injected ( 3 injections of $100 \mathrm{mg} / \mathrm{kg}$ i.p. every $8 \mathrm{~h}$ ) 3 weeks before brain retrieval to allow for sufficient time for newborn cell maturation. $B$, Left, Costaining for CldU and NeuN highlighting neurons that have been born and differentiated during the preceding 3 weeks. Scale bar, $100 \mu \mathrm{m}$. Right, Quantification of (ldU ${ }^{+} / \mathrm{NeuN}^{+}$cell densities. A significant addition of (Figure legend continues.) 


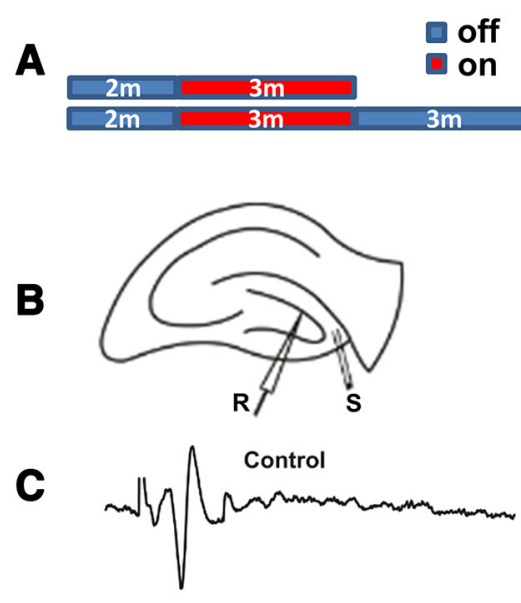

D

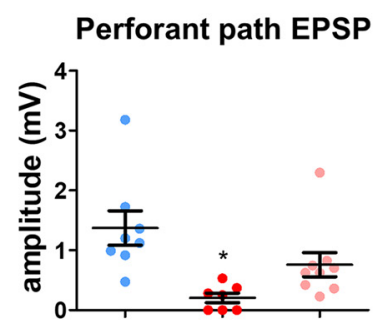

Control

VEGF on

VEGF on>off

E

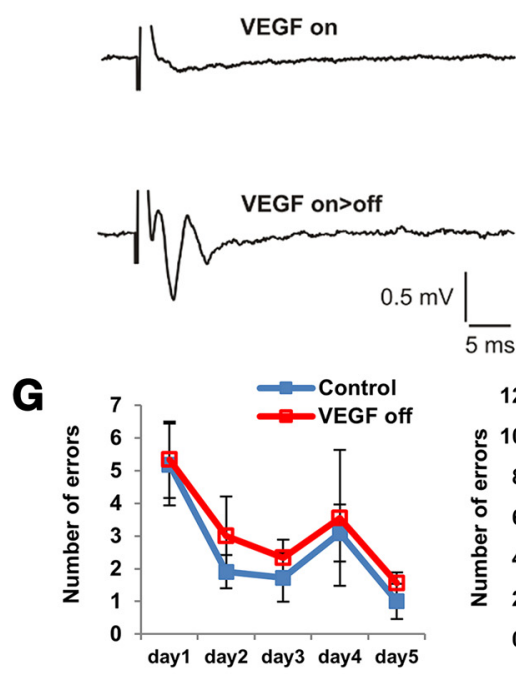

F Errors to reach the platform
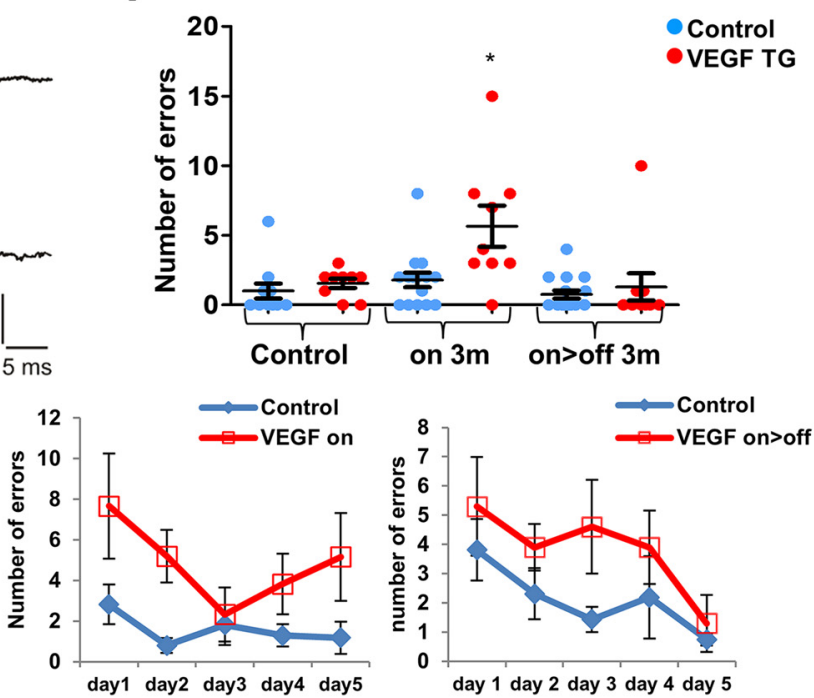

Figure 9. Regeneration of perforant path connectivity and spatial memory. $\boldsymbol{A}$, Experimental design for $\boldsymbol{B}-\boldsymbol{D}$. $\boldsymbol{B}$, Acute coronal slices from VEGF on and on $>$ off mice were stimulated at the afferent fibers of the perforant path (S), and EPSP was recorded at the upper blade of the GCL (R). C, Representative traces in control, on, and on $>$ off hippocampal slices. D, Peak EPSP amplitude at the stimulation of $16 \mathrm{~V}$ was measured. $\boldsymbol{E}$, RAWM testing. A group of double-transgenic animals and their littermate controls was tested at three time points: before VEGF induction, 3 months from inducing VEGF, and after 3 additional months of deinduction. A significantly higher number of errors to find the platform is found only in the VEGF on group. $F$, Impaired learning in the VEGF-on group is reflected in more erroneous trials before finding the escape platform. Three months after VEGF deinduction, learning abilities are fully restored. G, The numbers of errors during the training period at every time point. For statistical details, see Table $1 .{ }^{*} p<0.05$.

to the conclusion that newborn GCs are eliminated in the VEGF-on group subsequent to the $\mathrm{DCX}^{+}$stage.

An additional indication that prolonged VEGF exposure results in aberrant neurogenesis was obtained by following

\section{$\leftarrow$}

(Figure legend continued.) $\quad \mathrm{NeuN}^{+}$cells following VEGF deinduction but not when VEGF signaling was still ongoing. C, DCX and CD31 staining highlighting neuroblasts and blood vessels, respectively. Note ectopic DCX ${ }^{+}$cells in the hilus (inset 1) and in the ML (inset 2). Scale bar, 100 $\mu \mathrm{m}$. Quantification of $\mathrm{CD} 31^{+}$cells shows that blood vessels added by VEGF persists after its withdrawal (MVD, right); likewise, quantification of total $D C X^{+}$cell numbers shows that neuroblast production remains at approximately the same elevated levels after VEGF withdrawal. $D$, Costaining for DCX and CldU to label late (3 weeks old) neuroblasts, before completion of maturation. Quantification of late neuroblast density and percentage on right. $\boldsymbol{E}-\boldsymbol{H}$, Aberrant aspects of neurogenesis revealed by tracing $\mathrm{Gli}^{+} \mathrm{NSC}$ descendants. $\boldsymbol{E}$, Experimental scheme: Gli1-cre $e^{\text {ERT2 }}$ and Ai9 reporter mice were bred to the VEGF system. $\boldsymbol{F}$, Animals that inherited all four transgenes were fed by tamoxifen $(8 \mathrm{mg}, 1 / \mathrm{d}$ oral administration for $3 \mathrm{~d})$. Brains were retrieved for analysis according to the scheme. $\mathbf{G}$, Representative images of Gli ${ }^{+}$cells and their descendants with dendrite morphologies better seen in high-magnification insets. Note lack of dendritic spines in VEGF on dendrites (Giv) and their presence in the VEGF on $>$ off (Gvi). Arrows indicate NSCs and adult-born GCs according to the legends in $\boldsymbol{H}$. H, Hilus. Scale bar, 100 $\mu \mathrm{m} . \boldsymbol{H}$, Analysis for the percentage of cell types (NSCs and GCs) in each of the experimental protocols. For statistical details, see Table $1 .{ }^{*} p<0.01$.
NSC descendants using lineage tracing. Briefly, NSCs were marked by crossing Gli1-Cre $e^{E R T 2}$ mice (Ahn and Joyner, 2004) with floxed-Ai9 TdTomato reporter mice and bred onto the VEGF switchable system (Fig. 8E-H). NSCs and their descendants were then visualized at different time points after VEGF induction and tamoxifen administration (short tamoxifen pulses highlight NSCs, whereas longer tamoxifen pulses highlight their descendants). Results showed that, while at 1.5 months after VEGF induction, newborn GCs with normal appearance were still observed (Fig. 8Giii), 1.5 months later, normal GCs were no longer detected. Instead, cells projecting to unusual areas and abnormal cells devoid of dendritic spines and even cells with no projections were evident (Fig. 8Giv). Also, NSCs discernible by their radial morphology acquire the modified morphology in the sense of losing the apical fine processes and projecting some distal processes into the hilus in addition to the ML to where they are normally directed (Figs. $7 C, 8 G i i i, G v, G v i i)$. Newly formed GCs in the regenerated DG, visualized through lineage tracing as above, were shown to have normal morphology marked by proper development of dendritic spines, indicative of synapse formation (Fig. $8 \mathrm{Gvi}, \mathrm{G}$ - 


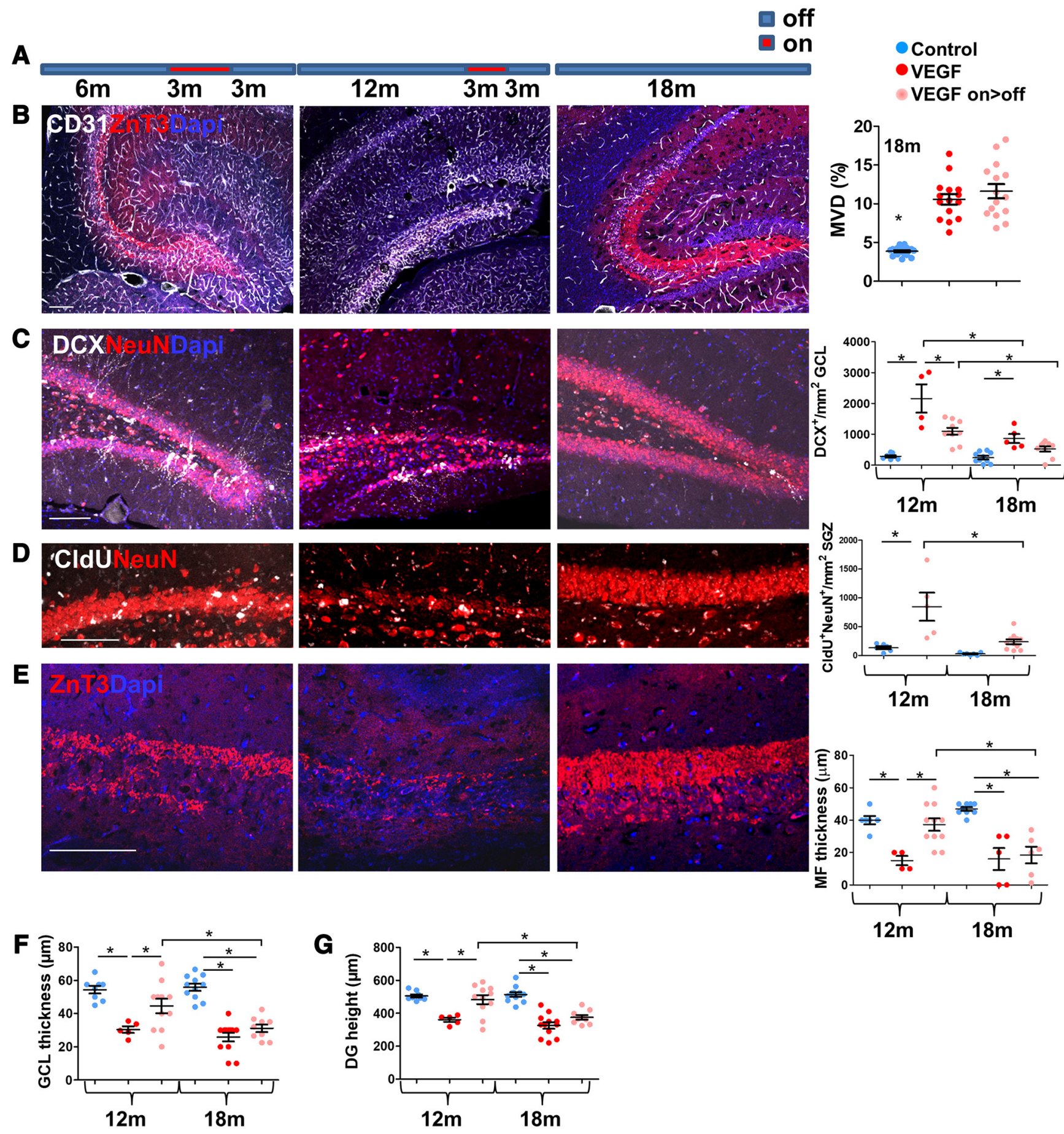

Figure 10. The regenerative potential of the DG is lost in old age. $A$, Experimental protocol: VEGF was induced at the ages of 6 or 12 months, maintained for 3 months in the on mode, and then deinduced. Brains were retrieved for analysis either by the end of the induction period (for measuring incurred damage) or 3 months after deinduction (i.e., when mice are 12 and 18 months old, respectively) for measuring the extent of structural repair. $\boldsymbol{B}$, Immunostaining for ZnT3 and CD31. Right, MVD quantification for 18-month-old animals. Old mice display angiogenic response to VEGF similarly to young mice. C, Immunostaining for DCX and NeuN. Right, DCX cell density quantification. D, CldU was injected 3 weeks before death, and CldU ${ }^{+} / \mathrm{NeuN}^{+}$cells were visualized (left) and quantified (right). $\boldsymbol{E}$, High-power field of CA3 ZnT3 staining. MF thickness (quantified in right) was measured as in Figure 1H. $F, G$, NeuN staining $(\boldsymbol{C}, \boldsymbol{D})$ was used to measure GCL thickness $(\boldsymbol{F})$ and DG height $(\boldsymbol{G})$ as in Figure $2 B$. Scale bars, $100 \mu \mathrm{m}$. For statistical details, see Table $1 .{ }^{*} p<0.05$.

vii). We summarized the relative numbers of NSC/GC normal and abnormal morphology of every experimental group in Figure $8 H$.

Together, findings suggest that neurogenesis in the repair phase is productive and has the capability of replacing lost neurons by the addition of newborn GC.
DG regeneration is marked by the restoration of functional GCs connectivity and regain of impaired learning and memory We have shown that newborn GCs during regeneration (on $>$ off) have a properly oriented MF and dendrites comprising dendritic spines, indicative of new synapse formation (Fig. 8Gvi,Gvii). To determine whether regenerated GCs (as in the protocol illus- 
trated in Fig. 9A) reestablish lost functional connections, we examined perforant path connectivity (i.e., the pathway connecting afferent entorhinal cortex with the DG and also constituting the major input pathway to the DG). To this end, afferent fibers of the perforant path were stimulated in acute coronal hippocampal slices, and EPSP was recorded in GCs located at the upper blade of the DG (Fig. 9B). A typical $1.5 \mathrm{mV}$ EPSP measured in the noninjured DG was found to be reduced to $0.2 \mathrm{mV}$ by the end of the 3 month exposure to VEGF, indicating a barely functional perforant path. Regeneration led to partial but highly significant perforant path recovery measured as $0.6 \mathrm{mV}$ EPSP and a response curve resembling intact DG (Fig. 9C,D). Together with findings that all measured EPSP responses were inhibited by the glutamatergic inhibitors APV and CNQX (data not shown), we conclude that regenerated DG GCs establish functional glutamatergic synapses with entorhinal cortex neurons.

Anticipating that a DG damage of the magnitude shown in the VEGF-on mice will lead to a significant cognitive deficit, we examined whether the anticipated cognitive loss is rectifiable by DG regeneration. To this end, mice were subjected to a RAWM test (Alamed et al., 2006; Fujisaki et al., 2014). Briefly, mice were first trained daily for 5 consecutive days to locate a submerged platform hidden in one of the arms, and their learning and memory skills were tested by determining the number of trial-and-error attempts required to find the hidden platform. Each mouse was trained and tested three times: before VEGF induction, 3 months after VEGF induction (VEGF on), and 3 months after VEGF deinduction (VEGF on $>$ off) (Fig. 9E). While there was no difference between control and VEGF groups at baseline, VEGFinduced DG damage led to learning/memory impairment, reflected by more erroneous attempts before finding the platform. Following regeneration, impaired learning/memory was fully rectified, equalizing the performance of most treated mice to that of untreated littermates (Fig. $9 F$ ). The $5 \mathrm{~d}$ training progress for each one of the time points is presented in Figure 9G. These results suggest that newly born neurons produced during the repair phase may be functional, at least with respect to spatial learning and memory.

\section{Regenerative potential of the DG is lost in old mice}

Considering that hippocampal neurogenesis in rodents precipitously declines with age reaching a negligible level by the age of 9-12 months (Kuhn et al., 1996; Ben Abdallah et al., 2010; Encinas et al., 2011; Licht et al., 2016), it was of interest to determine whether regenerative potential also declines with age. To this end, VEGF induction and subsequent deinduction (for a period of 3 months each) were delayed such that the onset of VEGF induction was postponed to the age of 6 or 12 months (implying that regeneration was examined in 12- and 18-month-old mice, respectively, instead of in 8-month-old mice, as before; Fig. 10A).

It was first required to ensure that a comparable DG injury is also elicited at older ages (i.e., that VEGF inducibility and responsiveness are not blunted with age). Preparatory experiments showed that, at least with respect to the angiogenic response of VEGF, the aged (18 month) hippocampus is as responsive as the young hippocampus (Fig. 10B). More directly, evaluation of the DG damage inflicted by VEGF exposure revealed a comparable decrease in DG cellularity and size in young and old mice (Fig. $10 B-F)$. Twelve-month-old mice were still capable of mounting an efficient repair, evidenced by restoration of DG cellularity, size, and presence of the MF axonal layer in the majority of animals (but not all) (Fig. 10 B,E,F). In contrast, 18-month-old mice appeared to have completely lost their regenerative capacity evidenced by a dramatically reduced production of both $\mathrm{DCX}^{+}$ neuroblasts and $\mathrm{NeuN}^{+}$neurons (Fig. 10C,D) and undetectable $\mathrm{ZnT}^{+} \mathrm{MF}$ (Fig. 10 B,E). Cognitive decline and restoration could not be measured in this group of animals measured in this age group due to their deteriorated physical state precluding RAWM testing. These findings thus indicate that, in parallel to the agerelated decay of DG neurogenesis, there is also a progressive loss in DG repair capability.

\section{Discussion}

The functional significance of adult hippocampal neurogenesis has been the subject for intensive research in the last three decades, with most studies attributing to added hippocampal neurons a role in learning and memory enhancement, depression, and social behavior (Lee and Agoston, 2010; Marín-Burgin and Schinder, 2012; Toda and Gage, 2018). Little is known, however, whether the capacity of neuron production during adult life also serves the purpose of postinjury regeneration (Peng and Bonaguidi, 2018). The proposition of adult neurogenesis designated for regeneration was addressed through inflicting substantial DGrestricted damage using two unrelated methods and monitoring subsequent DG regeneration. Importantly, in the two model systems used (i.e., DT-aided GC ablation and massive GC loss following sustained overexpression of ectopic VEGF), DG cellularity was dramatically reduced while NSCs were fully spared.

An intrinsic mechanism to cope with neuronal damage is of particular significance in the case of the DG given its exceptional vulnerability to many insults, such as virus-induced encephalitis (Wu et al., 2013), exposure to chemicals (Bruccoleri et al., 1998; Choi et al., 2014, 2017), adrenalectomy/adrenal insufficiency (Spanswick et al., 2007, 2011; Izumida et al., 2017), and Alzheimer's disease and frontotemporal lobe degeneration (Small et al., 2011; Armstrong et al., 2012; Adler et al., 2018). Our study adds yet another example for a selective DG vulnerability, namely, selective apoptosis of DG neurons following prolonged exposure to ectopic VEGF (a situation that can be physiologically relevant in the case of CNS tumors).

Could it be then that the DG neurogenic system serves as a backup system for homeostatic maintenance for this vulnerable organ? This would provide an additional rationale for the continued presence of NSCs in this specific locale. Notably, in comparison with the situation in mice where NSC-driven neurogenesis subsides with age, some findings show evidence for remaining neurogenesis in the adult human DG (Eriksson et al., 1998; Spalding et al., 2013; Boldrini et al., 2018), giving the option for a repair in old age.

Currently, we do not know why prolonged exposure to ectopic VEGF leads to hippocampal injury and, particularly, why the damage is restricted to DG GCs. Possible mechanisms of VEGFinduced neurotoxicity to be considered include the following: (1) Hyperexcitability and resultant glutamate toxicity due to increased LTP response, previously shown by us to be enhanced by VEGF in a reversible manner (Licht et al., 2011), a possibility also compatible with findings that NMDA receptor modulations in the hippocampus were shown to induce DG-specific degeneration while sparing the CA1 (Watanabe et al., 2016). (2) DGspecific damage could, in principle, be attributed to detrimental effects of ectopic neurogenesis (Cho et al., 2015). This possibility is, however, less likely considering that VEGF induces GCs death in aged mice (where neurogenesis is negligible). (3) DG selectivity of 
VEGF-induced damage might also be related to VEGF-induced microglia activation, which we found to be specific to the DG and precedes angiogenesis (Kreisel et al., 2019). Other possible explanations linked to the experimental tet system used were tested and precluded (Fig. 5). Regardless of the mechanism(s) underlying VEGF-induced neurotoxicity, both the magnitude of damage and its DG-restricted nature have provided us with a suitable platform for monitoring regeneration.

Attesting for the remarkable regenerative potential of the DG was a significant restoration of DG cellularity (although not always achieving full recovery), proper rewiring of regenerated neurons and reacquisition of lost spatial memory. The latter, however, was only demonstrated in the model of VEGF-induced DG injury because, in the DTR ${ }^{\text {pomc }}$ model, injured mice were still performing as well as untreated mice.

How the damage is sensed and the nature of factors triggering DG regeneration remains to be examined. Intriguingly, DG neurogenesis can be elicited not only in response to local signals but also in response to remote signals evidenced by a neurogenic response in the noninjured contralateral DG and even upon injury of other brain regions, such as following a traumatic brain injury or cortical stroke (Jin et al., 2001; Zepeda et al., 2013; X. Wang et al., 2016). Interestingly, in our regeneration models, the addition of newborn neurons fully replaced lost GCs, but the regenerated DG did not exceed its normal cellularity, suggesting that a size control mechanism may exist.

The study shows that DG regeneration is solely driven by resident NSCs, thus anticipating (and indeed shown) that agerelated NSC exhaustion will be reflected in age-related loss of regenerative potential. The ability to promote marked regeneration of DG morphology and functions by intrinsic stem cells is unique particularly when considering that SVZ-born NSCs, while capable of homing to remote injured brain areas (Nakatomi et al., 2002; Zhang et al., 2004; Grade et al., 2013) do not properly integrate and contribute to functional repair (Gould and Tanapat, 1997; Grade et al., 2013; Inta and Gass, 2015; Madathil and Saatman, 2015). One notable difference in this regard is that, in the case of the hippocampus, newborn neurons remain in the boundaries of the DG and their integration in the existing network takes place within their natural microenvironment.

Demonstrating selective DG vulnerability and the ability of DG NSCs to promote repair highlights the regenerative designation of DG neurogenesis in the same line with its roles in learning and memory and gives an explanation for its presence particularly in this unique brain compartment.

\section{References}

Adler DH, Wisse LE, Ittyerah R, Pluta JB, Ding SL, Xie L, Wang J, Kadivar S, Robinson JL, Schuck T, Trojanowski JQ, Grossman M, Detre JA, Elliott MA, Toledo JB, Liu W, Pickup S, Miller MI, Das SR, Wolk DA, et al. (2018) Characterizing the human hippocampus in aging and Alzheimer's disease using a computational atlas derived from ex vivo MRI and histology. Proc Natl Acad Sci U S A 115:4252-4257.

Ahn S, Joyner AL (2004) Dynamic changes in the response of cells to positive hedgehog signaling during mouse limb patterning. Cell 118:505-516.

Aimone JB, Deng W, Gage FH (2011) Resolving new memories: a critical look at the dentate gyrus, adult neurogenesis, and pattern separation. Neuron 70:589-596.

Alamed J, Wilcock DM, Diamond DM, Gordon MN, Morgan D (2006) Two-day radial-arm water maze learning and memory task: robust resolution of amyloid-related memory deficits in transgenic mice. Nat Protoc 1:1671-1679.

Armstrong RA, Carter D, Cairns NJ (2012) A quantitative study of the neu- ropathology of 32 sporadic and familial cases of frontotemporal lobar degeneration with TDP-43 proteinopathy (FTLD-TDP). Neuropathol Appl Neurobiol 38:25-38.

Beard C, Hochedlinger K, Plath K, Wutz A, Jaenisch R (2006) Efficient method to generate single-copy transgenic mice by site-specific integration in embryonic stem cells. Genesis 44:23-28.

Ben Abdallah NM, Slomianka L, Vyssotski AL, Lipp HP (2010) Early agerelated changes in adult hippocampal neurogenesis in C57 mice. Neurobiol Aging 31:151-161.

Boldrini M, Fulmore CA, Tartt AN, Simeon LR, Pavlova I, Poposka V, Rosoklija GB, Stankov A, Arango V, Dwork AJ, Hen R, Mann JJ (2018) Human hippocampal neurogenesis persists throughout aging. Cell Stem Cell 22:589-599.e5.

Bruccoleri A, Brown H, Harry GJ (1998) Cellular localization and temporal elevation of tumor necrosis factor-alpha, interleukin-1 alpha, and transforming growth factor-beta $1 \mathrm{mRNA}$ in hippocampal injury response induced by trimethyltin. J Neurochem 71:1577-1587.

Cho KO, Lybrand ZR, Ito N, Brulet R, Tafacory F, Zhang L, Good L, Ure K, Kernie SG, Birnbaum SG, Scharfman HE, Eisch AJ, Hsieh J (2015) Aberrant hippocampal neurogenesis contributes to epilepsy and associated cognitive decline. Nat Commun 6:6606.

Choi BY, Lee BE, Kim JH, Kim HJ, Sohn M, Song HK, Chung TN, Suh SW (2014) Colchicine induced intraneuronal free zinc accumulation and dentate granule cell degeneration. Metallomics 6:1513-1520.

Choi BY, Hong DK, Suh SW (2017) ZnT3 gene deletion reduces colchicineinduced dentate granule cell degeneration. Int J Mol Sci 18:E2189.

Collins M, Riascos D, Kovalik T, An J, Krupa K, Krupa K, Hood BL, Conrads TP, Renton AE, Traynor BJ, Bowser R (2012) The RNA-binding motif 45 (RBM45) protein accumulates in inclusion bodies in amyotrophic lateral sclerosis (ALS) and frontotemporal lobar degeneration with TDP-43 inclusions (FTLD-TDP) patients. Acta Neuropathol 124: 717-732.

Encinas JM, Michurina TV, Peunova N, Park JH, Tordo J, Peterson DA, Fishell G, Koulakov A, Enikolopov G (2011) Division-coupled astrocytic differentiation and age-related depletion of neural stem cells in the adult hippocampus. Cell Stem Cell 8:566-579.

Eriksson PS, Perfilieva E, Björk-Eriksson T, Alborn AM, Nordborg C, Peterson DA, Gage FH (1998) Neurogenesis in the adult human hippocampus. Nat Med 4:1313-1317.

Fujisaki K, Tsuruya K, Yamato M, Toyonaga J, Noguchi H, Nakano T, Taniguchi M, Tokumoto M, Hirakata H, Kitazono T (2014) Cerebral oxidative stress induces spatial working memory dysfunction in uremic mice: neuroprotective effect of tempol. Nephrol Dial Transplant 29:529-538.

Gould E, Tanapat P (1997) Lesion-induced proliferation of neuronal progenitors in the dentate gyrus of the adult rat. Neuroscience 80:427-436.

Grade S, Weng YC, Snapyan M, Kriz J, Malva JO, Saghatelyan A (2013) Brain-derived neurotrophic factor promotes vasculature-associated migration of neuronal precursors toward the ischemic striatum. PLoS One 8:e55039.

Gray WP, Sundstrom LE (1998) Kainic acid increases the proliferation of granule cell progenitors in the dentate gyrus of the adult rat. Brain Res 790:52-59.

Han HJ, Allen CC, Buchovecky CM, Yetman MJ, Born HA, Marin MA, Rodgers SP, Song BJ, Lu HC, Justice MJ, Probst FJ, Jankowsky JL (2012) Strain background influences neurotoxicity and behavioral abnormalities in mice expressing the tetracycline transactivator. J Neurosci 32:10574-10586.

Hattiangady B, Rao MS, Shetty AK (2004) Chronic temporal lobe epilepsy is associated with severely declined dentate neurogenesis in the adult hippocampus. Neurobiol Dis 17:473-490.

Heinemann U, Beck H, Dreier JP, Ficker E, Stabel J, Zhang CL (1992) The dentate gyrus as a regulated gate for the propagation of epileptiform activity. Epilepsy Res Suppl 7:273-280.

Houser CR (1992) Morphological changes in the dentate gyrus in human temporal lobe epilepsy. Epilepsy Res Suppl 7:223-234.

Inta D, Gass P (2015) Is forebrain neurogenesis a potential repair mechanism after stroke? J Cereb Blood Flow Metab 35:1220-1221.

Izumida $\mathrm{H}$, Takagi H, Fujisawa H, Iwata N, Nakashima K, Takeuchi S, Iwama S, Namba T, Komatu Y, Kaibuchi K, Oiso Y, Arima H, Sugimura Y (2017) NMDA receptor antagonist prevents cell death in the hippocampal dentate gyrus induced by hyponatremia accompanying adrenal insufficiency in rats. Exp Neurol 287:65-74. 
Jessberger S, Zhao C, Toni N, Clemenson GD Jr, Li Y, Gage FH (2007) Seizure-associated, aberrant neurogenesis in adult rats characterized with retrovirus-mediated cell labeling. J Neurosci 27:9400-9407.

Jin KL, Mao XO, Greenberg DA (2000) Vascular endothelial growth factor: direct neuroprotective effect in in vitro ischemia. Proc Natl Acad Sci U S A 97:10242-10247.

Jin K, Minami M, Lan JQ, Mao XO, Batteur S, Simon RP, Greenberg DA (2001) Neurogenesis in dentate subgranular zone and rostral subventricular zone after focal cerebral ischemia in the rat. Proc Natl Acad Sci U S A 98:4710-4715.

Kivelä R, Hemanthakumar KA, Vaparanta K, Robciuc M, Izumiya Y, Kidoya H, Takakura N, Peng X, Sawyer DB, Elenius K, Walsh K, Alitalo K (2019) Endothelial cells regulate physiological cardiomyocyte growth via VEGFR2-mediated paracrine signaling. Circulation 139:2570-2584.

Kovacs GG, Rozemuller AJ, van Swieten JC, Gelpi E, Majtenyi K, Al-Sarraj S, Troakes C, Bódi I, King A, Hortobágyi T, Esiri MM, Ansorge O, Giaccone G, Ferrer I, Arzberger T, Bogdanovic N, Nilsson T, Leisser I, Alafuzoff I, Ironside JW, et al. (2013) Neuropathology of the hippocampus in FTLD-tau with Pick bodies: a study of the BrainNet europe consortium. Neuropathol Appl Neurobiol 39:166-178.

Kreisel T, Wolf B, Keshet E, Licht T (2019) Unique role for dentate gyrus microglia in neuroblast survival and in VEGF-induced activation. Glia 67:594-618.

Krook-Magnuson E, Armstrong C, Bui A, Lew S, Oijala M, Soltesz I (2015) In vivo evaluation of the dentate gate theory in epilepsy. J Physiol 593: 2379-2388.

Kuhn HG, Dickinson-Anson H, Gage FH (1996) Neurogenesis in the dentate gyrus of the adult rat: age-related decrease of neuronal progenitor proliferation. J Neurosci 16:2027-2033.

Kukreja L, Shahidehpour R, Kim G, Keegan J, Sadleir KR, Russell T, Csernansky J, Mesulam M, Vassar RJ, Wang L, Dong H, Geula C (2018) Differential neurotoxicity related to tetracycline transactivator and TDP-43 expression in conditional TDP-43 mouse model of frontotemporal lobar degeneration. J Neurosci 38:6045-6062.

Lee C, Agoston DV (2010) Vascular endothelial growth factor is involved in mediating increased de novo hippocampal neurogenesis in response to traumatic brain injury. J Neurotrauma 27:541-553.

Licht T, Keshet E (2015) The vascular niche in adult neurogenesis. Mech Dev 138:56-62.

Licht T, Eavri R, Goshen I, Shlomai Y, Mizrahi A, Keshet E (2010) VEGF is required for dendritogenesis of newly born olfactory bulb interneurons. Development 137:261-271.

Licht T, Goshen I, Avital A, Kreisel T, Zubedat S, Eavri R, Segal M, Yirmiya R, Keshet E (2011) Reversible modulations of neuronal plasticity by VEGF. Proc Natl Acad Sci U S A 108:5081-5086.

Licht T, Rothe G, Kreisel T, Wolf B, Benny O, Rooney AG, Ffrench-Constant C, Enikolopov G, Keshet E (2016) VEGF preconditioning leads to stem cell remodeling and attenuates age-related decay of adult hippocampal neurogenesis. Proc Natl Acad Sci U S A 113:E7828-E7836.

Lu J, Manaenko A, Hu Q (2017) Targeting adult neurogenesis for poststroke therapy. Stem Cells Int 2017:5868632.

Madathil SK, Saatman KE (2015) IGF-1/IGF-R signaling in traumatic brain injury: impact on cell survival, neurogenesis, and behavioral outcome. In: Brain neurotrauma: molecular, neuropsychological, and rehabilitation aspects (Kobeissy FH, ed). Boca Raton, FL: CRC.

Maehlen J, Torvik A (1990) Necrosis of granule cells of hippocampus in adrenocortical failure. Acta Neuropathol 80:85-87.

Marín-Burgin A, Schinder AF (2012) Requirement of adult-born neurons for hippocampus-dependent learning. Behav Brain Res 227:391-399.

Mayford M, Bach ME, Huang YY, Wang L, Hawkins RD, Kandel ER (1996) Control of memory formation through regulated expression of a CaMKII transgene. Science 274:1678-1683.

McHugh TJ, Jones MW, Quinn JJ, Balthasar N, Coppari R, Elmquist JK, Lowell BB, Fanselow MS, Wilson MA, Tonegawa S (2007) Dentate gyrus NMDA receptors mediate rapid pattern separation in the hippocampal network. Science 317:94-99.

Melnikova T, Park D, Becker L, Lee D, Cho E, Sayyida N, Tian J, BandeenRoche K, Borchelt DR, Savonenko AV (2016) Sex-related dimorphism in dentate gyrus atrophy and behavioral phenotypes in an inducible tTa:APPsi transgenic model of Alzheimer's disease. Neurobiol Dis 96: 171-185.

Mignone JL, Kukekov V, Chiang AS, Steindler D, Enikolopov G (2004)
Neural stem and progenitor cells in Nestin-GFP transgenic mice. J Comp Neurol 469:311-324.

Moss J, Gebara E, Bushong EA, Sánchez-Pascual I, O’Laoi R, El M’Ghari I, Kocher-Braissant J, Ellisman MH, Toni N (2016) Fine processes of Nestin-GFP-positive radial glia-like stem cells in the adult dentate gyrus ensheathe local synapses and vasculature. Proc Natl Acad Sci U S A 113:E2536-E2545.

Myczek K, Yeung ST, Castello N, Baglietto-Vargas D, LaFerla FM (2014) Hippocampal adaptive response following extensive neuronal loss in an inducible transgenic mouse model. PLoS One 9:e106009.

Nakatomi H, Kuriu T, Okabe S, Yamamoto S, Hatano O, Kawahara N, Tamura A, Kirino T, Nakafuku M (2002) Regeneration of hippocampal pyramidal neurons after ischemic brain injury by recruitment of endogenous neural progenitors. Cell 110:429-441.

Oosthuyse B, Moons L, Storkebaum E, Beck H, Nuyens D, Brusselmans K, Van Dorpe J, Hellings P, Gorselink M, Heymans S, Theilmeier G, Dewerchin M, Laudenbach V, Vermylen P, Raat H, Acker T, Vleminckx V, Van Den Bosch L, Cashman N, Fujisawa H, et al. (2001) Deletion of the hypoxia-response element in the vascular endothelial growth factor promoter causes motor neuron degeneration. Nat Genet 28:131-138.

Palmiter RD, Cole TB, Quaife CJ, Findley SD (1996) ZnT-3, a putative transporter of zinc into synaptic vesicles. Proc Natl Acad Sci U S A 93: 14934-14939.

Peng L, Bonaguidi MA (2018) Function and dysfunction of adult hippocampal neurogenesis in regeneration and disease. Am J Pathol 188: 23-28.

Sierra A, Martín-Suárez S, Valcárcel-Martín R, Pascual-Brazo J, Aelvoet SA, Abiega O, Deudero JJ, Brewster AL, Bernales I, Anderson AE, Baekelandt V, Maletic-Savatic M, Encinas JM (2015) Neuronal hyperactivity accelerates depletion of neural stem cells and impairs hippocampal neurogenesis. Cell Stem Cell 16:488-503.

Sirerol-Piquer M, Gomez-Ramos P, Hernández F, Perez M, Morán MA, Fuster-Matanzo A, Lucas JJ, Avila J, Garcia-Verdugo JM (2011) GSK3 $\beta$ overexpression induces neuronal death and a depletion of the neurogenic niches in the dentate gyrus. Hippocampus 21:910-922.

Small SA, Schobel SA, Buxton RB, Witter MP, Barnes CA (2011) A pathophysiological framework of hippocampal dysfunction in ageing and disease. Nat Rev Neurosci 12:585-601.

Spalding KL, Bergmann O, Alkass K, Bernard S, Salehpour M, Huttner HB, Boström E, Westerlund I, Vial C, Buchholz BA, Possnert G, Mash DC, Druid H, Frisén J (2013) Dynamics of hippocampal neurogenesis in adult humans. Cell 153:1219-1227.

Spanswick SC, Epp JR, Keith JR, Sutherland RJ (2007) Adrenalectomyinduced granule cell degeneration in the hippocampus causes spatial memory deficits that are not reversed by chronic treatment with corticosterone or fluoxetine. Hippocampus 17:137-146.

Spanswick SC, Lehmann H, Sutherland RJ (2011) A novel animal model of hippocampal cognitive deficits, slow neurodegeneration, and neuroregeneration. J Biomed Biotechnol 2011:527201.

Steward O (1994) Electroconvulsive seizures upregulate astroglial gene expression selectively in the dentate gyrus. Brain Res Mol Brain Res 25:217224.

Takeda A, Tamano H (2018) Is vulnerability of the dentate gyrus to aging and amyloid-beta1-42 neurotoxicity linked with modified extracellular $\mathrm{Zn}(2+)$ dynamics? Biol Pharm Bull 41:995-1000.

Toda T, Gage FH (2018) Review: adult neurogenesis contributes to hippocampal plasticity. Cell Tissue Res 373:693-709.

Toda T, Parylak SL, Linker SB, Gage FH (2019) The role of adult hippocampal neurogenesis in brain health and disease. Mol Psychiatry 24:67-87.

Tu DG, Chang YL, Chou CH, Lin YL, Chiang CC, Chang YY, Chen YC (2018) Preventive effects of taurine against d-galactose-induced cognitive dysfunction and brain damage. Food Funct 9:124-133.

van Praag H, Schinder AF, Christie BR, Toni N, Palmer TD, Gage FH (2002) Functional neurogenesis in the adult hippocampus. Nature 415: 1030-1034.

Wang F, Fangfang Z, Guo X, Chen W, Yao W, Liu H, Lyu C, Zhang Y, Fan C (2018) Effects of volatile organic compounds and carbon monoxide mixtures on learning and memory, oxidative stress, and monoamine neurotransmitters in the brains of mice. Toxicol Ind Health $34: 178-187$. 
Wang X, Gao X, Michalski S, Zhao S, Chen J (2016) Traumatic brain injury severity affects neurogenesis in adult mouse hippocampus. J Neurotrauma 33:721-733.

Watanabe Y, Müller MK, von Engelhardt J, Sprengel R, Seeburg PH, Monyer H (2016) Age-dependent degeneration of mature dentate gyrus granule cells following NMDA receptor ablation. Front Mol Neurosci 8:87.

Wu YJ, Schulz H, Lin CC, Saar K, Patone G, Fischer H, Hübner N, Heimrich B, Schwemmle M (2013) Borna disease virus-induced neuronal degeneration dependent on host genetic background and prevented by soluble factors. Proc Natl Acad Sci U S A 110:1899-1904.

Yamasaki TR, Blurton-Jones M, Morrissette DA, Kitazawa M, Oddo S,
LaFerla FM (2007) Neural stem cells improve memory in an inducible mouse model of neuronal loss. J Neurosci 27:11925-11933.

Yu TS, Washington PM, Kernie SG (2016) Injury-induced neurogenesis: mechanisms and relevance. Neuroscientist 22:61-71.

Zepeda A, Aguilar-Arredondo A, Michel G, Ramos-Languren LE, Escobar ML, Arias C (2013) Functional recovery of the dentate gyrus after a focal lesion is accompanied by structural reorganization in the adult rat. Brain Struct Funct 218:437-453.

Zhang R, Zhang Z, Wang L, Wang Y, Gousev A, Zhang L, Ho KL, Morshead C, Chopp M (2004) Activated neural stem cells contribute to strokeinduced neurogenesis and neuroblast migration toward the infarct boundary in adult rats. J Cereb Blood Flow Metab 24:441-448. 